\title{
The Crucial Roles of Intermediate Metabolites in Cancer
}

\author{
Sisi Huang' \\ Zhiqin Wang ${ }^{2,3}$ \\ Liang Zhao ${ }^{4}$
}

'Hengyang School of Medicine, University of South China, Hengyang, Hunan, 42I00I, People's Republic of China; ${ }^{2}$ Department of Geriatric Neurology, Xiangya Hospital, Central South University, Changsha, Hunan, 410008, People's Republic of China; ${ }^{3}$ National Clinical Research Center for Geriatric Disorders, Xiangya Hospital, Central South University, Changsha, Hunan, 410008, People's Republic of China; ${ }^{4}$ Department of Hematology, Xiangya Hospital, Central South University, Changsha, Hunan, 410008, People's Republic of China
Correspondence: Zhiqin Wang Department of Geriatric Neurology, Xiangya Hospital, Central South University, 87 Xiangya Road, Changsha, Hunan, 4I0008, People's Republic of China

Tel +86-73I-89753752

Email zhiqin.wang@csu.edu.cn

Liang Zhao

Department of Hematology, Xiangya Hospital, Central South University, 87

Xiangya Road, Changsha, Hunan, 4I0008, People's Republic of China

Tel +86-73I-89753730

Fax +86-73I-84327497

Email liang_zhao08@163.com

\begin{abstract}
Metabolic alteration, one of the hallmarks of cancer cells, is important for cancer initiation and development. To support their rapid growth, cancer cells alter their metabolism so as to obtain the necessary energy and building blocks for biosynthetic pathways, as well as to adjust their redox balance. Once thought to be merely byproducts of metabolic pathways, intermediate metabolites are now known to mediate epigenetic modifications and protein post-transcriptional modifications (PTM), as well as connect cellular metabolism with signal transduction. Consequently, they can affect a myriad of processes, including proliferation, apoptosis, and immunity. In this review, we summarize multiple representative metabolites involved in glycolysis, the pentose phosphate pathway (PPP), the tricarboxylic acid (TCA) cycle, lipid synthesis, ketogenesis, methionine metabolism, glutamine metabolism, and tryptophan metabolism, focusing on their roles in chromatin and protein modifications and as signal-transducing messengers.
\end{abstract}

Keywords: oncometabolites, extra-metabolic functions, epigenetic modification, signaling transduction, post-transcriptional modifications

\section{Introduction}

Cell metabolism comprises an intricate network of chemical reactions that sustain normal growth and reproduction. Metabolism comprises catabolism and anabolism, the former supplying energy and the latter producing the necessary cellular components for cell proliferation. Cancers are characterized by uncontrolled cell proliferation and heterogeneous microenvironment. On the one hand, cancer cells adjust their metabolic preference to balance their energy needs with the need to generate biosynthetic precursors for growth; ${ }^{1}$ on the other hand, they develop nutrient-scavenging strategies to survive under nutrient-starvation and oxygenlimiting conditions. ${ }^{2}$ Cancer cells undergo extensive metabolic alterations, including in glycolysis, mitochondrial biogenesis, lipid metabolism, and the pentose phosphate pathway (PPP), ${ }^{3}$ by either reprogramming the activities of existing metabolic pathways or rewiring new connections. ${ }^{4}$

Metabolic reprogramming in cancer cells results in the accumulation or depletion of intermediate metabolites through a variety of mechanisms. ${ }^{5}$ The first one is the alteration of metabolic enzyme activity. For example, during glycolysis, the preferred way for cancer cells to obtain energy and biosynthetic building blocks, the activation of glycolysis-related enzymes leads to the accumulation of a series of glycolytic intermediates. ${ }^{6}$ In contrast, the loss of the activities of succinate dehydrogenase $(\mathrm{SDH})$ and fumarate hydratase $(\mathrm{FH})$ contributes to the accumulation of 
succinate and fumarate, respectively. ${ }^{7}$ Secondly, mutations arising in cancer cells can result in neomorphic enzyme activity. For instance, wild-type isocitrate dehydrogenase (IDH) converts isocitrate to alpha-ketoglutarate $(\alpha-\mathrm{KG})$, while IDH with specific single-site mutations further catalyzes the conversion of $\alpha-\mathrm{KG}$ to 2-hydroxyglutarate (2-HG). ${ }^{8}$ Thirdly, cancer cells generate several active byproducts of metabolic pathways, such as reactive oxygen species (ROS), $\mathrm{NAD}^{+} / \mathrm{NADH}$, and $\mathrm{NADP}^{+} / \mathrm{NADPH}$.

Since the discovery of the oncogenic roles of some mitochondrial metabolites, such as $2-\mathrm{HG}$, succinate, and fumarate, research has increasingly focused on investigating the roles of these "oncometabolites" in cancer. ${ }^{9,10}$ Oncometabolites affect processes such as epigenetic modifications, post-transcriptional modifications (PTMs), and signaling transduction. ${ }^{10}$ Metabolic remodeling can promote DNA hypermethylation and histone hyperacetylation, thereby silencing tumor suppressor genes and promoting tumorigenesis. ${ }^{11}$ As for PTMs, a wide spectrum of metabolites can conjugate to proteins and regulate their functions. Various types of PTMs have been reported, among which acetylation and succinylation have attracted extensive research interest. ${ }^{12}$ To illustrate metabolite sensing and signaling, Wang and colleagues proposed a ternary model consisting of a sensor, a transducer, and an effector. ${ }^{13}$ In their model, metabolites were first recognized by sensors. Transducers subsequently transmitted the signal information to effectors, which finally stimulated the corresponding biological reactions. ${ }^{13}$ They grouped a variety of metabolite sensing events into three modes: metabolite sensor-mediated signaling ( $\mathrm{MeSr}$ ), metabolitesensing module (MeS), and sensing by conjugating (SC). ${ }^{13}$ In the first category, a sensor physically interacts with the metabolite and transduces the signals to downstream. In the metabolite-sensing module, molecules like protein complexes are disrupted by the metabolites without direct binding through a structurally conserved site, causing downstream changes. The last mode is the conjugation of metabolites to proteins or nucleotides, causing functional alterations. $^{13}$

Besides oncometabolites, numerous intermediate metabolites can directly bind to proteins or nucleotides, leading to their dysfunction. In addition, these intermediate metabolites can act as ligands for transmembrane receptors, activating downstream signaling cascades. In this review, we will introduce the roles of multiple intermediates classified by metabolic pathways in cancer. For each intermediate metabolite, we will briefly introduce its source, and then discuss in-depth its effects on epigenetic modifications, PTM, and signaling transduction (Table 1).

\section{Metabolites in Glycolysis}

Glycolysis consists of energy-requiring and energyreleasing phases. ${ }^{14}$ In the first step of the energyrequiring phase, hexokinase catalyzes the phosphorylation of glucose, generating glucose-6-phosphate (G6P). G6P is then transformed to glyceraldehyde-3-phosphate (GA3P) through several steps. GA3P is oxidized to 1,3-bisphosphoglycerate (1,3-BPG) by glyceraldehyde 3-phosphate dehydrogenase (GAPDH), which is the first step in the energy-releasing phase. 1,3-BPG loses a phosphate and becomes 3-phosphoglycerate (3-PG), which is further converted to 2-phosphoglycerate (2-PG) by phosphoglycerate mutase (PGAM). After losing one molecule of $\mathrm{H}_{2} \mathrm{O}$, 2-PG is converted to phosphoenolpyruvate (PEP). Dephosphorylation of PEP yields pyruvate. Under oxygenrich conditions, pyruvate is transferred to the mitochondria and participates in the tricarboxylic acid (TCA) cycle; under hypoxic conditions; however, pyruvate is converted to lactate by lactate dehydrogenase (LDH) ${ }^{14}$ (Figure 1).

\section{I,3-BPG}

1,3-BPG brings about PTMs to a variety of glycolytic proteins. During the modification process, active 1,3-BPG binds to lysine residues in these proteins, generating 3-phosphoglyceryl-lysine (pgK) in an enzymeindependent manner. Under high-glucose conditions, the generation of pgK inhibits glycolysis and redirects glycolytic intermediates to alternative biosynthetic pathways, which represents a crucial feedback regulatory mechanism (SC mode). ${ }^{15}$ Additionally, 1,3-BPG can activate PGAM1 by directly phosphorylating its histidine residues (Figure 1), thereby maintaining glycolytic flux and supporting cell growth in HCT116 or MDA-MB-231 cancer cells. $^{16}$

\section{3-PG and 2-PG}

3-PG competitively occupies the active site of phosphogluconate dehydrogenase (PGD), the rate-limiting enzyme in the PPP, resulting in impaired PGD function and the suppression of the PPP flux ${ }^{17}$ (Figure 1). Increased expression of PGAM1 in tumor cells leads to enhanced 3-PG consumption, PPP activation, and increased 2-PG levels. 2-PG can further downregulate the level of 3-PG by enhancing the phosphoglycerate dehydrogenase (PHGDH)-mediated production of 
Table I Roles of Metabolites in Chromatin and Protein Modifications, Signal Transduction and Their Effects on Cancer

\begin{tabular}{|c|c|c|c|}
\hline Metabolites & Roles in Modification or Signal Transduction & Effects on Cancer & References \\
\hline \multirow[t]{2}{*}{ I,3-BPG } & pgK modification & Feedback regulation of glycolysis & {$[15]$} \\
\hline & PGAMI phosphorylation & Maintaining glycolytic flux and support cell growth & {$[16]$} \\
\hline $\begin{array}{l}\text { 3-PG and } \\
2-P G\end{array}$ & Inhibiting PGD, activate PHGDH & Balancing the glycolysis and anabolic biosynthesis & {$[17]$} \\
\hline PEP & Suppressing SERCA-Ca ${ }^{2+}$-NFAT signaling & Suppressing the antitumor function of $\mathrm{T}$ cells & {$[18,19]$} \\
\hline \multirow[t]{4}{*}{ Lactate } & Inhibiting HDAC & $\begin{array}{l}\text { Histone hyperacetylation and deregulating gene } \\
\text { transcription }\end{array}$ & [33] \\
\hline & Histone lactylation & Stimulating gene transcriptions & [34] \\
\hline & PHD-mediate signaling & Angiogenic and proliferative effects & {$[22,24]$} \\
\hline & ArgI/GPR8I/MAVS signaling & Driving immune evasion & {$[25-30,32]$} \\
\hline $\begin{array}{l}\text { Ru-5-P and } \\
6-P G L\end{array}$ & $\begin{array}{l}\text { Disrupting the LKBI-MO25-STRAD complex; Binding to } \\
\text { Src and inhibiting PP2A activity }\end{array}$ & Regulating AMPK activity & {$[38,39]$} \\
\hline \multirow[t]{2}{*}{$\begin{array}{l}2-\mathrm{HG} \\
\text { Succinate } \\
\text { Fumarate }\end{array}$} & Inhibiting TET/KDMs & DNA/histone hypermethylation & $\begin{array}{l}{[53,54,56-} \\
60] \\
{[68-73]} \\
{[68]}\end{array}$ \\
\hline & Inhibiting PHD & Inhibiting HIF signaling and pseudohypoxia response & $\begin{array}{l}{[61-63]} \\
{[74,75]} \\
{[73]}\end{array}$ \\
\hline \multirow[t]{2}{*}{ Succinate } & Lysine succinylation & $\begin{array}{l}\text { Maintaining the activity of multiple chromatin and } \\
\text { metabolic enzymes }\end{array}$ & {$[76-78]$} \\
\hline & SUCNRI-mediated signaling & $\begin{array}{l}\text { Activating oncogenic signaling pathways, including } \\
\text { ERK, STAT3, and PI3K/HIF-I } \alpha\end{array}$ & {$[80,81]$} \\
\hline Fumarate & Succination & Activating multiple glycolytic enzymes & [83-87] \\
\hline $\begin{array}{l}\text { Ac-CoA } \\
\text { Acetate }\end{array}$ & Acetylation & $\begin{array}{l}\text { Acetylation of histones and proteins, promoting } \\
\text { tumorigenesis }\end{array}$ & $\begin{array}{l}{[95-} \\
98,100,101] \\
{[104]}\end{array}$ \\
\hline Acetate & GPR signaling & Preventing cancer cells from stress-induced damage & {$[106]$} \\
\hline LCFA & FABP5 mediated signaling & $\begin{array}{l}\text { SLCFA and ULCFA orchestrally regulate PPAR } \beta / \delta \\
\text { signaling }\end{array}$ & {$[107,108]$} \\
\hline AA & Binding to $\mathrm{BRAF}^{\mathrm{V} 600 \mathrm{E}}$ & $\begin{array}{l}\text { Activation of MEK-ERK signaling and promoting } \\
\text { tumor growth }\end{array}$ & {$[111-113]$} \\
\hline \multirow[t]{3}{*}{$3-\mathrm{OHB}$} & Inhibiting Class I HDAC & Increasing histone acetylation & [118] \\
\hline & Kbhb modification & Activating multiple oncogene promoters & {$[119,120]$} \\
\hline & GPR I09A signaling & $\begin{array}{l}\text { Enhancing colonic cancer cells apoptosis and } \\
\text { depressing survival }\end{array}$ & {$[|2|]$} \\
\hline \multirow[t]{2}{*}{ SAM } & Methylation & Methylating numerous nucleic acids and histones & {$[123-127]$} \\
\hline & Repressing $\beta$-catenin and IL-6 signaling & Reducing inflammation & {$[128,129]$} \\
\hline
\end{tabular}


Table I (Continued).

\begin{tabular}{|l|l|l|l|}
\hline Metabolites & Roles in Modification or Signal Transduction & Effects on Cancer & References \\
\hline GSH & S-glutathionylation & $\begin{array}{l}\text { S-glutathionylation of proteins, protecting cancer } \\
\text { cells from ROS attack }\end{array}$ & {$[133-135]$} \\
\hline Kyn and KA & AhR signaling & Pro-carcinogenic effects & {$[139-143]$} \\
\hline KA & Glutamate receptors & Promoting glioma cell proliferation & {$[145]$} \\
\hline
\end{tabular}

Abbreviations: I,3-BPG, I,3-bisphosphoglycerate; 3-PG, 3-phosphoglycerate; 2-PG, 2-phosphoglycerate; PEP, phosphoenolpyruvate; 6-PGL, 6-phosphogluconolactone; Ru5-P, ribulose-5-phosphate; 2-HG, 2-hydroxyglutarate; Ac-CoA, Acetyl-CoA; LCFA, long chain fatty acid; AA, acetoacetate; 3-OHB, 3-hydroxybutyrate; SAM, S-adenosylmethionine; GSH, glutathione; Kyn, kynurenine; KA, kynurenic acid.

3-phosphohydroxypyruvate (pPYR) (Figure 1), which is the first committed step in serine synthesis. Through these mechanisms, tumor cells precisely adjust 3-PG and 2-PG levels, thereby regulating glycolysis and anabolic biosynthesis. $^{17}$

\section{PEP}

In intratumoral $\mathrm{T}$ cells, PEP suppresses the activity of sarco/endoplasmic reticulum $\mathrm{Ca}(2+)$-ATPase (SERCA), a calcium transporter that mediates $\mathrm{Ca}^{2+}$ uptake into the endoplasmic reticulum, resulting in $\mathrm{Ca}^{2+}$ accumulation in

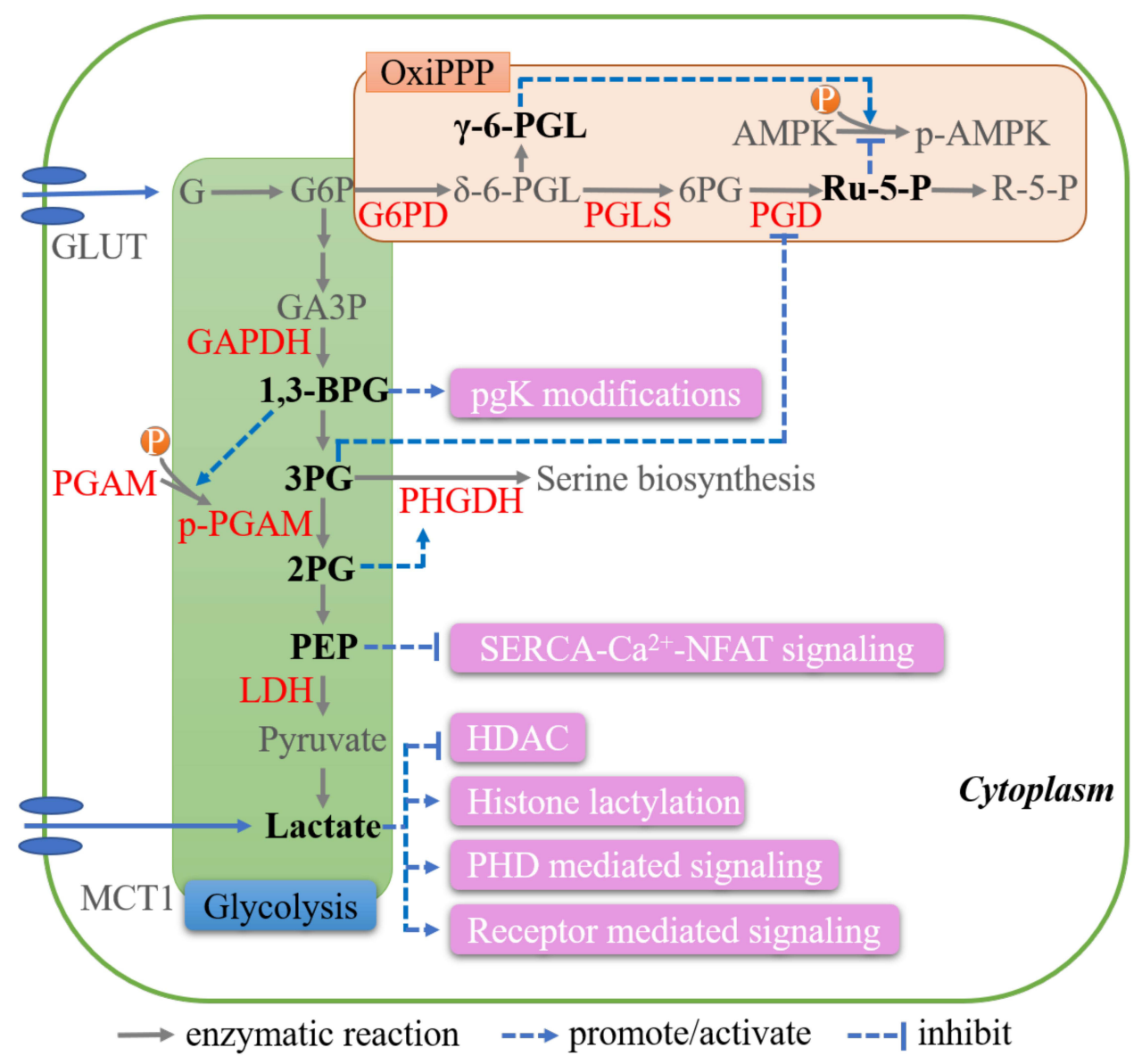

Figure I Key metabolites in glycolysis and oxidative PPP. Schematic representations of the biologic effects of those metabolites, including I,3-BPG, 3PG, 2PG, PEP, lactate, $\gamma$ 6-PGL and Ru-5-P, are in pink.

Abbreviations: PPP, pentose phosphate pathway; G6P, glucose 6-phosphate; GA3P, glyceraldehyde-3-phosphate; GAPDH, glyceraldehyde 3-phosphate dehydrogenase; I,3-BPG, I,3-bisphosphoglycerate; PGAM, phosphoglycerate mutase; 3-PG, 3-phosphoglycerate; 2-PG, 2-phosphoglycerate; PEP, phosphoenolpyruvate; LDH, lactate dehydrogenase; PHGDH, phosphoglycerate dehydrogenase; G6PD, glucose-6-phosphate dehydrogenase; $\delta$-6-PGL, $\delta$-6-phosphogluconolactone; $\gamma$-6-PGL, $\gamma-6$-phosphogluconolactone; PGLS, 6-phosphogluconolactonase; 6PG, 6-phosphogluconate; PGD, phosphogluconate dehydrogenase; Ru-5-P, ribulose-5-phosphate; R-5-P, ribose5-phosphate. 
the cytosol and further nuclear factor of activated $\mathrm{T}$ cells (NFAT) signaling activation, which is vital for $\mathrm{T}$ cells to exert their antitumor effects. ${ }^{18,19}$ This process of metabolite sensing and signaling can be classified as the MeS mode.

\section{Lactate}

Due to higher glucose-to-lactate flux, lactate overproduction is commonly detected in a subset of cancer cells, especially under hypoxic conditions. In oxygenated tumor cells, monocarboxylate transporter 1 (MCT1) can also mediate lactate import from hypoxic cancer cells ${ }^{20,21}$ (Figure 1).

Although widely known as an energy source, lactate displays active nonmetabolic characteristics. Lactate can inhibit $\alpha-K G$-dependent prolyl hydroxylase domain proteins (PHDs), which are involved in the hydroxylation of hypoxia-inducible factor 1-alpha (HIF-1 $\alpha$ ) and IкB kinase $\beta$ (IKK $\beta$ ). Inhibition of HIF- $1 \alpha$ leads to its stabilization, leading to the activation of HIF-1-mediated vascular endothelial growth factor (VEGF) signaling. ${ }^{22}$ Meanwhile, the inhibition of IKK $\beta$ hydroxylation results in $\mathrm{IKB} \alpha$ degradation, which activates nuclear factor kappa $\mathrm{B}$ (NF-kB) signaling. ${ }^{23}$ The effects of lactate on VEGF and NF- $\mathrm{KB}$ signaling can be classified as the MeS mode. Lactate can also interrupt the association between PHDs and N-Myc downstream-regulated protein (NDRG3) by directly binding to the latter in a manner that is independent of HIFs, which is an MeSr mode. This prevents the proteasomal degradation of NDRG3 and further activates Raf/ERK signaling, contributing to angiogenic and proliferative effects in cancer cells. ${ }^{24}$

In terms of driving immune evasion, the lactateinduced expression of arginase 1 (Arg1) promotes the functional polarization of tumor-associated macrophages (TAMs). ${ }^{25,26}$ In breast cancer, lactate was reported to induce TAM polarization through the ERK/STAT3 pathway. ${ }^{27}$ There are several examples of $\mathrm{MeSr}$ mode about lactate driving immune evasion. G protein-coupled receptor 81 (GPR81) is a lactate receptor that is highly expressed in multiple cancer cell lines. ${ }^{28}$ Lactate-GPR81 signaling stimulates the expression of programmed cell death ligand 1 (PD-L1) through the transcriptional coactivator TAZ, thereby suppressing interferon-gamma production in lung cancer. ${ }^{29,30}$ Lactate also suppresses innate immune responses in cancer. By binding to GPR81, lactate inactivates yes-associated protein (YAP) and further disrupts the interaction of YAP and NF- $\kappa \mathrm{B}$ in macrophages, resulting in the reduced production of macrophage proinflammatory cytokine. ${ }^{31}$ Furthermore, Zhang et al reported that lactate prevented the aggregation of mitochondrial antiviral-signaling protein (MAVS) by directly binding to its transmembrane domain. This suppressed the production of downstream type I interferons triggered by retinoic acid-inducible gene I-like receptor (RLR)-MAVS signaling, impairing cancer immunosuppression. ${ }^{32}$

Lactate also regulates gene expression by inhibiting histone deacetylases (HDACs), ${ }^{33}$ and can provide the lactyl group for lysine residues in histone tails, known as histone lactylation. Histone lactylation is active in TAMs, implying that this process has a role in immune surveillance. ${ }^{34}$

\section{Metabolites in the PPP}

The PPP consists of oxidative and nonoxidative phases, and leads to the production of metabolites and NADPH, which are pivotal for nucleotide biosynthesis, lipogenesis, and the maintenance of redox homeostasis. In the first step, G6P is oxidized to $\delta$-6-phosphogluconolactone $(\delta$ 6-PGL) by glucose-6-phosphate dehydrogenase (G6PD). Then, one carbon of hydrolytically unstable $\delta$-6-PGL is cleaved by 6-phosphogluconolactonase (PGLS), yielding 6-phosphogluconate (6-PG). 6-PG is further converted to ribulose-5-phosphate ( $\mathrm{Ru}-5-\mathrm{P})$ by PGD. Ru-5-P is isomerized into ribose-5-phosphate (R-5-P), which serves as the main building block for ribonucleotide synthesis. ${ }^{35}$ Notably, there is another form of 6-PGL- $\gamma$-6PGL-that is generated by the intramolecular rearrangement of $\delta$ 6PGL. It is relatively stable, represents a "dead-end" byproduct, and is not subsequently involved in the PPP (Figure 1).

\section{Ru-5-P and 6-PGL}

AMP-activated protein kinase (AMPK), a central metabolic sensor, is activated by upstream kinases and inactivated by phosphatase-mediated dephosphorylation. Liver kinase B1 homolog (LKB1) can form a complex with STE20-related adaptor protein (STRAD) and mouse protein 25 (MO25), acting as a major upstream activator of AMPK. ${ }^{36}$ Protein phosphatase 2A (PP2A) is a serine/threonine protein phosphatase that dephosphorylates AMPK at Thr172, thereby inactivating it. ${ }^{37} \mathrm{Ru}-5-\mathrm{P}$ can disrupt the LKB1-MO25STRAD complex, resulting in the inactivation of AMPK. ${ }^{38}$ In contrast, $\gamma$-6PGL binds to Src and inhibits PP2A activity by dephosphorylation, leading to AMPK activation ${ }^{39}$ (Figure 1). The action of Ru-5-P and $\gamma$-6PGL belongs to 
the MeS and MeSr mode, respectively. Cancer cells exhibit an active oxidative PPP, accompanied by decreased $\gamma$-6PGL and increased Ru-5-P levels. These alterations collectively inactivate AMPK, activate acetyl-CoA carboxylase 1, and, finally, enhance lipogenesis and tumor growth. ${ }^{38,39}$

\section{Metabolites in the TCA Cycle}

The TCA cycle, also called the Krebs cycle or the citric acid cycle, comprises a series of enzyme-catalyzed reactions and is the major energy production pathway in cells. $^{40}$ The third step is catalyzed by IDH, in which isocitrate undergoes oxidation to form $\alpha-\mathrm{KG}$, releasing NADH. $\alpha-K G$ is further converted to succinate, which is enzymatically catalyzed to fumarate by SDH. Fumarate is further oxidized to malate by FH. Finally, malate is oxidized to oxaloacetate (OAA) by malate dehydrogenase $(\mathrm{MDH})$. Notably, MDH catalyzes the interconversion of malate and OAA. There are two isoforms of $\mathrm{MDH}$, namely $\mathrm{MDH} 1$ and $\mathrm{MDH} 2$, which are localized to the cytoplasm and mitochondria, respectively. Similarly, IDH has three isoforms-cytosolic IDH1 as well as mitochondrial IDH2 and IDH3 - with IDH3 primarily functioning in normal enzymatic processes ${ }^{40}$ (Figure 2).

\section{2-HG}

2-HG consists of two enantiomers, namely D-2-HG (also known as R-2-HG) and L-2-HG (also known as S-2-HG) (Figure 2). 2-HG has attracted extensive research interest since the discovery of the neomorphic enzymatic activity of mutant IDH (mIDH) in 2009. ${ }^{8,10,41}$ Specific missense mutations in both IDH1 and IDH2 result in a neomorphic enzymatic activity that catalyzes $\alpha-\mathrm{KG}$ to D-2-HG, but not L-2-HG. The most common mutations are Arg132 in IDH1 and Arg172 plus Arg140 in IDH2, occurring in $\sim 80 \%$ of low-grade gliomas and $\sim 20 \%$ of cases of acute myeloid leukemia (AML), ${ }^{42-44}$ as well as in a spectrum of other malignancies, including cartilaginous tumors, intrahepatic cholangiocarcinoma, and angioimmunoblastic $\mathrm{T}$ cell lymphoma. ${ }^{45,46}$ In addition to being produced by $\mathrm{mIDH}$ in the TCA cycle, 2-HG can also be generated through several promiscuous enzymatic reactions. PHGDH, which normally catalyzes the first step of serine

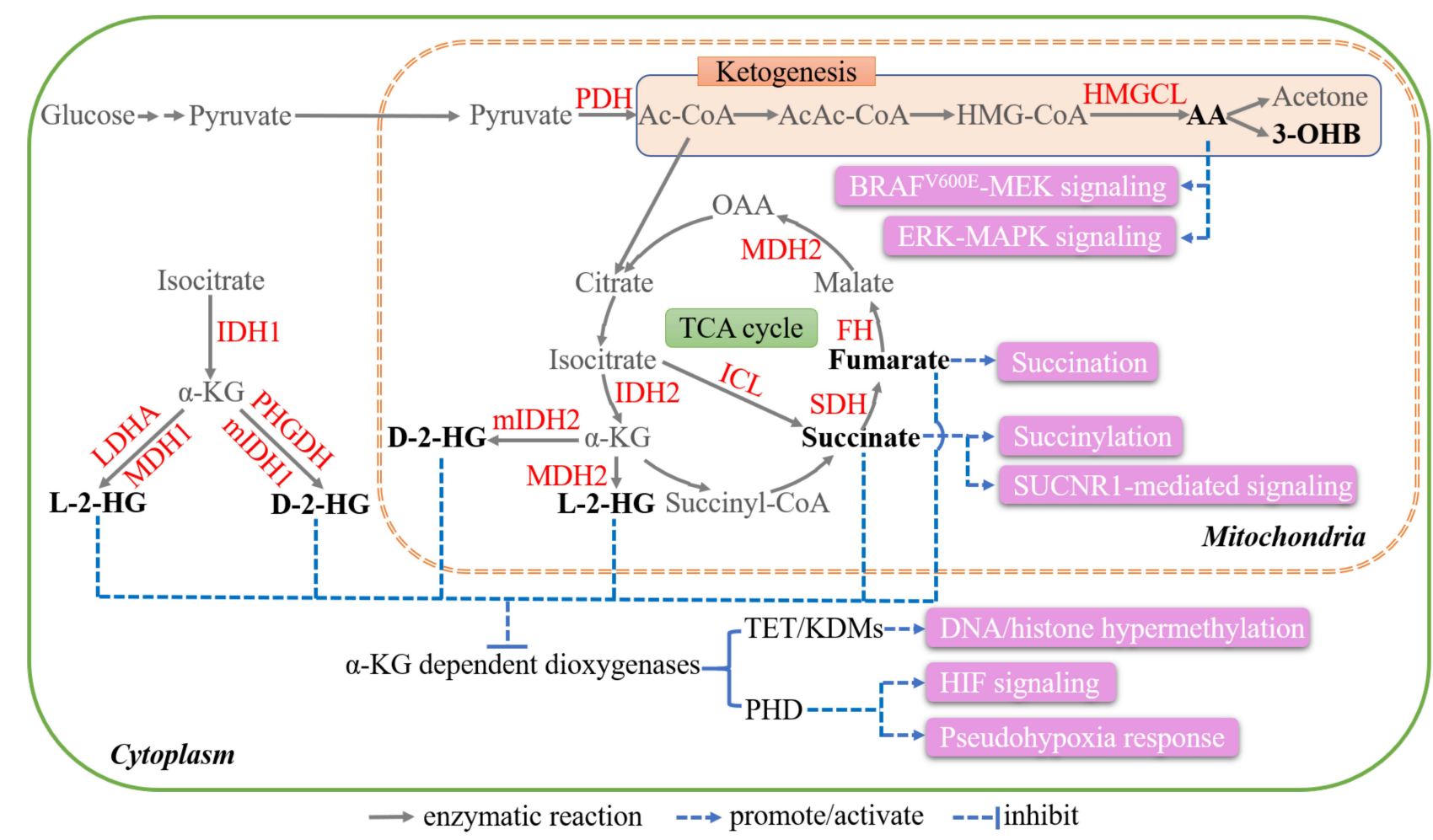

Figure 2 Key metabolites in TCA cycle and ketogenesis. The blue arrows and pink boxes highlight the extrametabolic functions of 2-HG, succinate, fumarate, AA, and 3-OHB.

Abbreviations: TCA cycle, tricarboxylic acid cycle; PDH, pyruvate dehydrogenase; IDH, isocitrate dehydrogenase; SDH, succinate dehydrogenase; FH, fumarate hydratase; $\alpha-K G$, alpha-ketoglutarate; 2-HG, 2-hydroxyglutarate; $M D H$, malate dehydrogenase; OAA, oxaloacetate; PHGDH, phosphoglycerate dehydrogenase; LDH, lactate dehydrogenase; ICL, isocitrate lyase; Ac-CoA, acetyl-CoA; AcAc-CoA, acetoacetyl-CoA; HMG-CoA, 3-hydroxy-3-methylglutaryl-CoA; HMGCL, 3-hydroxy-3-methylglutarylCoA lyase; 3-OHB, 3-hydroxybutyrate. 
biosynthesis, has been reported to be a source of D-2-HG in human breast cancer cell lines at quite low efficiency. ${ }^{47}$ In contrast, and surprisingly, L-2-HG is produced through the activities of $\mathrm{MDH}$ and lactate dehydrogenase A (LDHA). MDH catalyzes the production of L-2-HG in mammals, although this reaction is $10^{7,8}$ times less efficient when compared with OAA production. ${ }^{48}$ LDHA has been identified as the major L-2-HG-producing enzyme under hypoxic conditions $^{49}$ (Figure 2). D-2-hydroxyglutarate dehydrogenase (D2HGDH) $)^{50,51}$ and L-2-hydroxyglutarate dehydrogenase $(\mathrm{L} 2 \mathrm{HGDH})^{52}$ catalyze the conversion of D-2-HG and L-2-HG to $\alpha-K G$, respectively. Mutations in these two enzymes result in 2-HG accumulation and lead to 2-hydroxyglutaric acidurias (2HGAs)..$^{50,52}$

2-HG functions as an antagonist of $\alpha-K G$ as they have highly similar structures. ${ }^{45}$ Crystallographic structural studies revealed that 2-HG competitively occupies the active binding sites of multiple $\alpha$-KG-dependent enzymes, including the JmjC domain-containing histone demethylases (KDMs) and the ten-eleven translocation (TET) family of 5-methylcytosine $(5 \mathrm{mC})$ hydroxylases, and hence inhibits their activities. ${ }^{53-55}$ These enzymes remove methyl moieties through sequential reactions, the inhibition of which by 2-HG increases global DNA methylation and epigenetically silences multiple proteins with known and postulated roles in tumor suppression ${ }^{53}$ (Figure 2).

Histone demethylases are classified into two subfamilies, ie, the lysine demethylase 1 (KDM1) subfamily and the JmjC domain-containing KDMs (consisting of over 30 enzymes in humans, including KDM2, KDM3, KDM4, KDM5, KDM6, and others). ${ }^{56}$ Enzymes in the latter group are the major targets of D-2-HG. The related inhibition potencies vary, with KDM4A/JMJD2A being the most sensitive to D-2-HG, followed by KDM4C/JMJD2C, KDM2A/FBXL11, AlkB homolog 2 (ALKBH2), factor inhibiting HIF (FIH), PHD, and BBOX-1. ${ }^{54}$ Studies showed that the addition of D-2-HG or the stable overexpression of mIDH1 augments histone demethylation in glioma, including $\mathrm{H} 3 \mathrm{~K} 4, \mathrm{H} 3 \mathrm{~K} 9, \mathrm{H} 3 \mathrm{~K} 27$, and $\mathrm{H} 3 \mathrm{~K} 79$, an effect that can be counteracted by $\alpha-K G$ treatment. ${ }^{53,57}$ D-2-HG activates the mechanistic (previously mammalian) target of rapamycin (mTOR) signaling pathway in brain cancer by inhibiting $\mathrm{KDM} 4 \mathrm{~A},{ }^{58}$ which is an $\mathrm{MeSr}$ mode.

TET sequentially converts $5 \mathrm{mC}$ first to 5-hydroxymethylcytosine $(5 \mathrm{hmC})$, then to 5 -formylcytosine, and finally to 5 -carboxylcytosine. ${ }^{59}$ Biochemical assays showed that D-2-HG exerts a direct inhibitory effect on recombinant TET2 (Figure 2), which can be rescued by $\alpha$ KG. mIDH expression leads to the consistent reduction of TET2-dependent 5hmC levels. ${ }^{53}$ Moreover, both mIDH expression and TET2 silencing impair hematopoietic differentiation, implying that they have similar proleukemogenic effects. ${ }^{60}$

2-HG can also modulate the activity of several $\alpha$-KGdependent dioxygenases independently of epigenetic alterations. PHD, which is involved in the hydroxylation of HIF1 $\alpha$, was the first dioxygenase reported to be inhibited by 2-HG (MeSr mode). ${ }^{61,62}$ The inhibition of hydroxylation leads to HIF-1 $\alpha$ stabilization and the subsequent activation of genes containing HIF response elements (HREs), such as glycolytic enzymes, further contributing to tumor development. ${ }^{63}$ Additionally, D-2-HG has been reported to directly inhibit $\mathrm{ALKBH} 2,{ }^{54}$ a protein that repairs DNA damage caused by alkylating agents. Cells with $\mathrm{mIDH}$ accumulate double-strand breaks (DSBs) in their DNA, leading to genetic instability. ${ }^{64}$

\section{Succinate}

Succinate accumulation results primarily from loss-offunction mutations in SDH, which are found in a variety of cancer types, such as paraganglioma/pheochromocytoma (PGL/PCC), renal carcinoma, ovarian cancer, neuroblastoma, and gastrointestinal stromal tumor. ${ }^{65,66}$ Impairment of SDH activity can also lead to succinate accumulation. For example, tumor necrosis factor receptor-associated protein 1 (TRAP1) downregulates SDH activity by inhibiting respiratory complex II. ${ }^{67}$ Tumor-associated inflammatory responses can also suppress SDH activity, while isocitrate lyase (ICL) also likely contributes, as it directly converts isocitrate to succinate ${ }^{66}$ (Figure 2).

Like 2-HG, succinate can competitively inhibit $\alpha-K G-$ dependent KDMs and TETs, ${ }^{68}$ resulting in epigenetic alterations. Succinate promotes proliferation, epithelial-tomesenchymal transition (EMT), migration, and invasion by regulating the activities of a plethora of downstream genes. ${ }^{69-72}$ For example, increased succinate levels due to SDH mutations lead to DNA and histone hypermethylation in PGL/PCC, thereby suppressing EMT and neuroendocrine differentiation. ${ }^{69,73}$ Succinate also inhibits PHD and impairs HIF-1 $\alpha$ signaling (MeSr mode) ${ }^{74,75}$ (Figure 2).

Besides, succinate provides a succinyl moiety for lysine succinylation, a PTM that occurs in both chromatin and metabolic enzymes such as GLUT1, LDHA, and $\mathrm{GAPDH},{ }^{76}$ regulating their activities in cancer (SC 
mode) ${ }^{10,77,78}$ (Figure 2). For example, Li et al proved that succinylation of LDHA decreased its lysosomal degradation, promoting cell proliferation, invasion, and migration in gastric cancer. ${ }^{79}$

In addition, succinate can activate signaling pathway by the MeSr mode. Succinate binds to GPR91 (also known as succinate receptor 1 [SUCNR1]), which leads to increased VEGF expression and further triggers downstream signaling cascades, including those associated with extracellular regulated kinase (ERK) 1/2 and signal transducer and activator of transcription 3 (STAT3). ${ }^{80}$ Succinate secreted by cancer cells binds to GPR91, further activating PI3K/HIF-1 $\alpha$ signaling and triggering TAM polarization (Figure 2). This promotes cancer cell migration, invasion, and metastasis. ${ }^{81}$

\section{Fumarate}

Abnormal fumarate accumulation is attributed to inactivating mutations in $\mathrm{FH}$, which have been reported in skin leiomyomata, uterine fibroids, and papillary renal cell cancer. ${ }^{82}$ Fumarate appears to be multifaceted. ${ }^{10}$ Like $2-\mathrm{HG}$ and succinate, fumarate can allosterically inhibit $\alpha$-KG-dependent enzymes, including KDMs, TETs, and PHDs (MeSr mode), ${ }^{68,73}$ regulating the epigenetic landscape and producing pseudohypoxia. A distinct PTM related to fumarate is succination, during which the thiol group of a cysteine residue is converted to S-(2-succino)-cysteine $(2 \mathrm{SC})^{83}$ (Figure 2). Fumarate accumulation affects the normal succination of glycolytic enzymes, adiponectin, cytoskeletal proteins, and endoplasmic reticulum chaperones, impairing their functions. ${ }^{84,85}$ For instance, when succinated, Kelch-like ECH-associated protein-1 (KEAP1) is dissociated from nuclear factor erythroid 2-related factor 2 (NRF2). The latter is then stabilized, translocated to the nucleus, and modulated the transcription of several genes involved in antioxidant signaling and cytoprotection. ${ }^{86,87}$ In addition, the direct binding of fumarate to glutathione ${ }^{88}$ or glutathione succination ${ }^{89}$ leads to persistent oxidative stress and cellular senescence.

\section{Metabolites in Lipid Synthesis Acetyl-CoA}

Acetyl-CoA (Ac-CoA) is the main intermediate for lipid synthesis and is located in several cellular compartments, including the cytosol, mitochondria, and the nucleus. Generally, pyruvate is transferred to the mitochondria and decarboxylated to Ac-CoA by pyruvate dehydrogenase $(\mathrm{PDH}) .{ }^{90}$ Interestingly, Ac-CoA synthetase (ACSS) is another major enzyme that catalyzes the ATP-dependent incorporation of acetate into Ac-CoA. In mammalian cells, there are two ACSSs, namely, mitochondrial ACSS1 and cytosolic ACSS2. The expression of ACCS1 is markedly upregulated in multiple tumors. ${ }^{91}$ Under hypoxia, mitochondrial citrate is preferentially shuttled to the cytoplasm and converted to Ac-CoA and OAA by ATP citrate lyase (ACL). ${ }^{92}$ Acetate uptake, which is catalyzed by ACSS2, is also responsible for increased AcCoA levels. ${ }^{93}$ Reductive glutamine metabolism by IDH1 is another source of Ac-CoA under hypoxic conditions ${ }^{94}$ (Figure 3).

Ac-CoA is the starting material for fatty acid synthesis, while also being indispensable for the acetylation of histones and proteins (SC mode). There is a strong correlation between Ac-CoA levels and global histone acetylation. ${ }^{95,96}$ By modulating epigenetic alterations, Ac-CoA regulates the expression of numerous genes and ultimately promotes tumorigenesis. ${ }^{97}$ For example, in pancreatic ductal adenocarcinoma harboring KRAS mutations, ACL-mediated H3K27 acetylation ( $\mathrm{H} 3 \mathrm{~K} 27 \mathrm{ac})$ is increased, thereby promoting tumor development. ${ }^{98} \mathrm{H} 3 \mathrm{~K} 27 \mathrm{ac}$ due to upregulated AcCoA level also promotes the progression and chemoresistance of nasopharyngeal carcinoma. ${ }^{99}$ In human hepatocellular carcinoma, hypoxic cells show increased histone $\mathrm{H} 3$ acetylation due to an increase in Ac-CoA levels catalyzed by ACCS, which promotes lipid synthesis and tumor growth. ${ }^{100}$ Numerous proteins are also modulated through post-translational acetylation. For example, when acetylated at K540, 546, and 554, ACL tends to be stabilized, leading to increased Ac-CoA production through a feedforward mechanism ${ }^{101}$ (Figure 3). After K413 acetylation, mutant IDH2 (mIDH2) R140Q presents higher enzyme activity, producing sufficient 2-HG for the transformation in AML. ${ }^{102}$

\section{Acetate}

Exogenous acetate is mainly derived from saccharolytic fermentation in the colon, but can also be obtained from other sources, such as ethanol oxidation. Endogenously, acetate is generated via deacetylation and hydrolysis reactions that release acetyl groups. Recent studies have shown that acetate is produced de novo from pyruvate, via either ROSdependent oxidative decarboxylation or incomplete oxidation by ketoacid dehydrogenases (KDHs) in a thiamine- and glutathione-dependent manner ${ }^{103}$ (Figure 3).

As previously mentioned, acetate maintains the AcCoA pool in cancer cells, thereby influencing multiple AcCoA-associated biological processes. ${ }^{104}$ Acetate is also an 


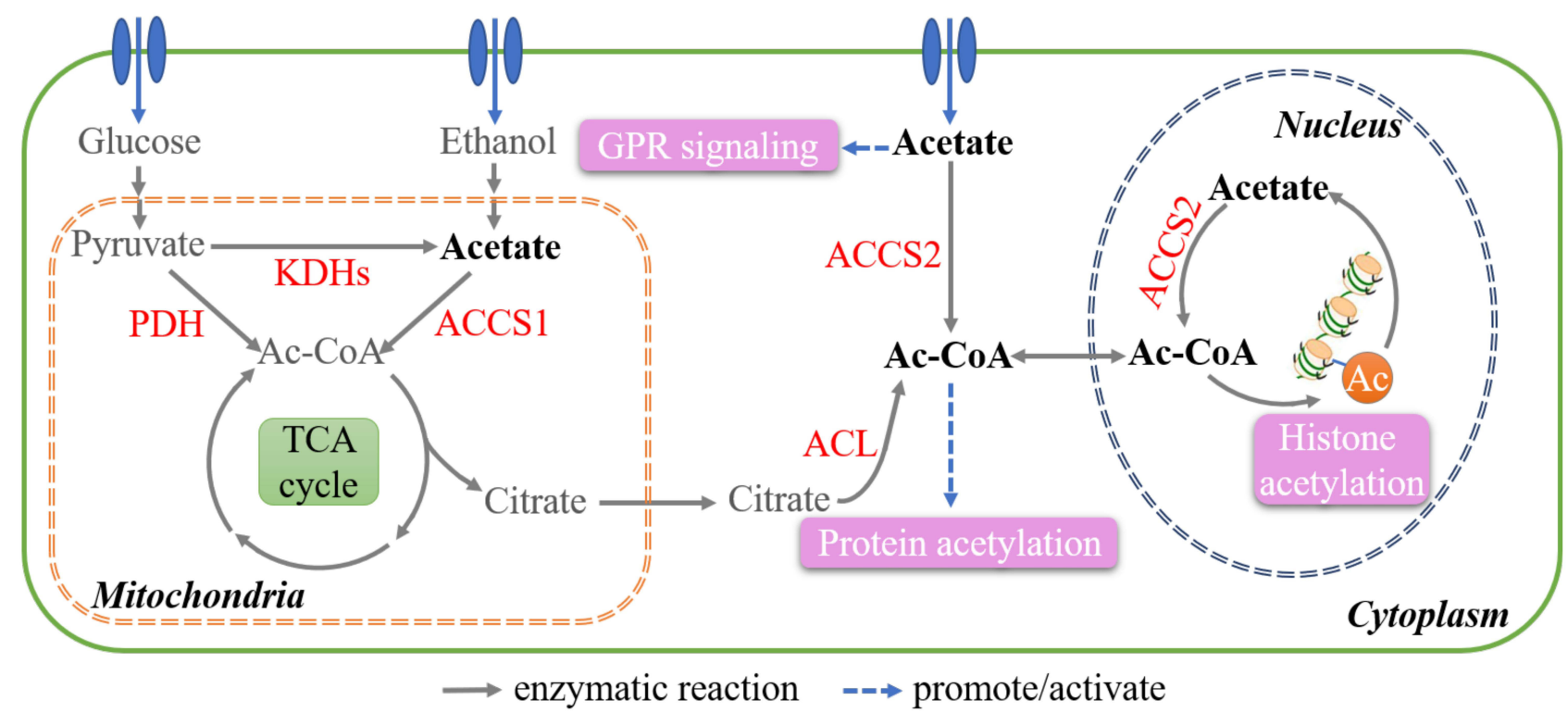

Figure 3 Key metabolites in lipid synthesis. Schematic diagram shows the Ac-CoA pool in different cell compartments. The functions of Ac-CoA and acetate outside metabolism are marked in pink.

Abbreviations: Ac-CoA, acetyl-CoA; PDH, pyruvate dehydrogenase; ACSS, Ac-CoA synthetase; ACL, ATP citrate lyase; KDHs, ketoacid dehydrogenases.

agonist of free fatty acid receptors (FFARs), which belong to the GPR family. Acetate activates FFAR2 in 3T3 fibroblasts, potentiating their malignant transformation. ${ }^{105} \mathrm{In}$ breast cancer, acetate-GPR signaling, which belongs to the MeSr mode, activates p38 mitogen-activated protein kinase (MAPK) and, subsequently, heat shock protein 27 (HSP27), thereby preventing stress-induced damage ${ }^{106}$ (Figure 3).

\section{Long Chain Fatty Acids (LCFA)}

Besides the role of energy source, LCFA also functions as signaling molecules. By displacing retinoic acid, saturated LCFA (SLCFA) binds to and inhibits fatty acid-binding protein 5 (FABP5) (MeSr mode). This suppresses the nuclear localization of peroxisome proliferator-activated receptor $\beta / \delta(\operatorname{PPAR} \beta / \delta)$, inhibiting the growth of carcinoma cells in vitro and in vivo. ${ }^{107,108}$ Interestingly, unsaturated LCFA (ULCFA) displays opposing effects. ${ }^{107}$

\section{Metabolites in the Ketogenesis Pathway}

In a fasted state, the body switches to breaking down fatty acids to ketone bodies (ketogenesis) to satisfy the energy requirements of key organs, including the brain, muscles, and other tissues. Ketogenesis occurs primarily in the mitochondria and begins with the condensation of AcCoA to acetoacetyl-CoA (AcAc-CoA). Subsequently,
3-hydroxy-3-methylglutaryl-CoA synthase (HMGCS) catalyzes the condensation of Ac-CoA and AcAc-CoA to form 3-hydroxy-3-methylglutaryl-CoA (HMG-CoA), which is further cleaved to acetoacetate (AA) by 3-hydroxy-3-methylglutaryl-CoA lyase (HMGCL). AA is then either dehydrogenized to 3-hydroxybutyrate (3-OHB) or decarboxylated to acetone. Finally, AA, 3-OHB, and AcAc-CoA acetone are transferred to the circulation and taken up by cells as alternative energy sources ${ }^{109}$ (Figure 2).

\section{$\mathrm{AA}$ and $3-\mathrm{OHB}$}

AA has been reported to activate ERK1/2 and p38 MAPK signaling in primary cultured rat hepatocytes in a ROS- and oxidative stress-dependent manner ${ }^{110}$ (Figure 2). Kang et al conducted a systematic screen for metabolic synthetic lethal partners of $\mathrm{BRAF}^{\mathrm{V} 600 \mathrm{E}}$ and found that $\mathrm{HMGCL}$ and HMGCS1 could specifically promote the growth of $\mathrm{BRAF}^{\mathrm{V} 600 \mathrm{E}}$-positive melanoma. ${ }^{111}$ The authors further demonstrated that $\mathrm{AA}$ bound to $\mathrm{BRAF}^{\mathrm{V} 600 \mathrm{E}}$, which enhanced the binding of $\mathrm{BRAF}^{\mathrm{V} 600 \mathrm{E}}$ and MEK1, thereby promoting the activation of MEK-ERK signaling (MeSr mode). ${ }^{11,112}$ Meanwhile, a different study reported that a high-fat ketogenic diet could increase serum AA concentrations, resulting in the enhanced growth of tumors derived from $\mathrm{BRAF}^{\mathrm{V} 600 \mathrm{E}}$-positive melanoma cells in xenografted mice. ${ }^{113}$ Conversely, both reducing circulating AA levels with hypolipidemic agents and treating with an inhibitory 
AA homolog could effectively attenuate the growth of $\mathrm{BRAF}^{\mathrm{V} 600 \mathrm{E}}$-positive tumors. ${ }^{113}$ Collectively, these findings suggest that AA mediates the crosstalk between the ketogenesis metabolic pathway and the MAPK signaling pathway (Figure 2).

Of note, 3-OHB is known to have functions beyond metabolism, including inhibiting HDACs and transducing signals through GPRs, effects that are closely correlated with diabetes and lifespan. ${ }^{114-117}$ Similarly, 3-OHB could inhibit Class I HDACs in cancer cells, which increases histone acetylation. ${ }^{118}$ Moreover, the generation of lysine $\beta$-hydroxybutyrylation (Kbhb), a novel type of histone posttranslational modification, is specifically attributed to 3-OHB. This new epigenetic regulatory is enriched in active gene promoters and closely linked with gene expression. ${ }^{119}$ For example, p53 is a well-known tumor suppressor gene. Its activity was significantly attenuated after Kbhb modification, leading to reduced cell growth arrest and apoptosis in cancer cells. ${ }^{120}$

As an intracellular signal mediator, 3-OHB also works as the only endogenous ligand of G-protein coupled receptors 109A (GPR109A), which is a potent tumor suppressor. In colonic epithelial cells, 3-OHB activates GPR109A, enhancing colonic cancer cells apoptosis and depressing survival (MeSr mode). ${ }^{121}$

\section{Metabolites in Methionine Metabolism \\ S-Adenosyl-Methionine}

S-adenosyl-methionine (SAM) is produced from methionine through the activity of methionine adenosyltransferase $2 \mathrm{~A}$ (MAT2A), which represents the first step in the methionine cycle. In the following step, which is catalyzed by methyltransferases (MTs), SAM donates the methyl group and is converted to S-adenosyl-homocysteine (SAH) ${ }^{122}$ (Figure 4).

As a universal methyl donor, SAM can greatly influence the methylation status of nucleic acids ${ }^{123}$ and histones, ${ }^{124}$ thereby modulating diverse and critical cellular processes in cancer (SC mode). For example, SAM inhibits the expression of urokinase-type plasminogen activator (UPA) and matrix metalloproteinase-2 (MMP-2) through the hypermethylation of their promoters, which suppresses invasiveness and tumorigenesis in prostate ${ }^{125}$ and breast cancer. ${ }^{126}$ Moreover, SAM can reverse the hypomethylation of the promoters of the oncogenes c-Myc and H-Ras, resulting in the inhibition of cell growth in gastric and colon cancer. ${ }^{127}$
SAM is also reported to reduce inflammation by repressing $\beta$-catenin and interleukin-6 (IL-6) signaling in liver and colon cancer, ${ }^{128,129}$ and also exerts proapoptotic effects through the ERK1/2 and STAT3 pathways in osteosarcoma cells ${ }^{130}$ (Figure 4). However, further studies are needed to elucidate the mechanism underlying its role in signaling transduction.

\section{Glutamine Metabolism Glutathione}

Glutamine is another substrate that is vital for energy production and macromolecule biosynthesis in cancer cells. Glutamine is transported into cells and converted to glutamate by mitochondrial glutaminases (GLSs). Glutamate has two major metabolic fates. It can either be converted to $\alpha-K G$ by glutamate dehydrogenase (GLUD) or aminotransferases and used for energy production in the TCA cycle or is first converted to $\gamma$-glutamylcysteine by glutamate-cysteine ligase (GCL) and then to glutathione (GSH) by GSH synthetase (GSS) ${ }^{131}$ GSH exists in both thiol-reduced and disulfideoxidized forms, namely, GSH and GSSG, respectively. GSH can be oxidized to GSSG by GSH peroxidase, while GSSG can be reverse-catalyzed to GSH by GSH reductase ${ }^{132}$ (Figure 4).

GSH is a well-known antioxidant. Abundant GSH in tumor cells protects themselves through the detoxification of carcinogens and the scavenging of free radicals. In terms of PTM, GSH binds to the cysteine residues of proteins, a process called S-glutathionylation, thereby protecting them from ROS attack. A growing number of GSH protein targets have been identified, including P53, HSP27, thioredoxin, caspase-3, and NF- $\mathrm{kB}$, involving a vast number of cellular processes (SC mode). ${ }^{133-135}$ The S-glutathionylation of histone H3, a GSH target, can lead to altered chromatin structure and nucleosome instability. ${ }^{136}$

\section{Tryptophan Metabolism}

Tryptophan (Trp) is an essential amino acid. A small fraction of Trp enter either serotonin or indole pathway, which are mainly occurred in nervous or innate immune system, respectively. Over $95 \%$ of free Trp is degraded by the kynurenine (Kyn) pathway (KP), which is closely related to cancer progression. In the KP, Trp is firstly converted to $\mathrm{N}$-formylkynurenine by indoleamine-2,3-dioxygenase 1 (IDO1), IDO2, and tryptophan-2,3-dioxygenase (TDO), which is the rate-limiting step. N-formylkynurenine is then catalyzed by kynurenine formamidase (AFMID) to produce Kyn. Kyn is further converted to 3-hydroxykynurenine 


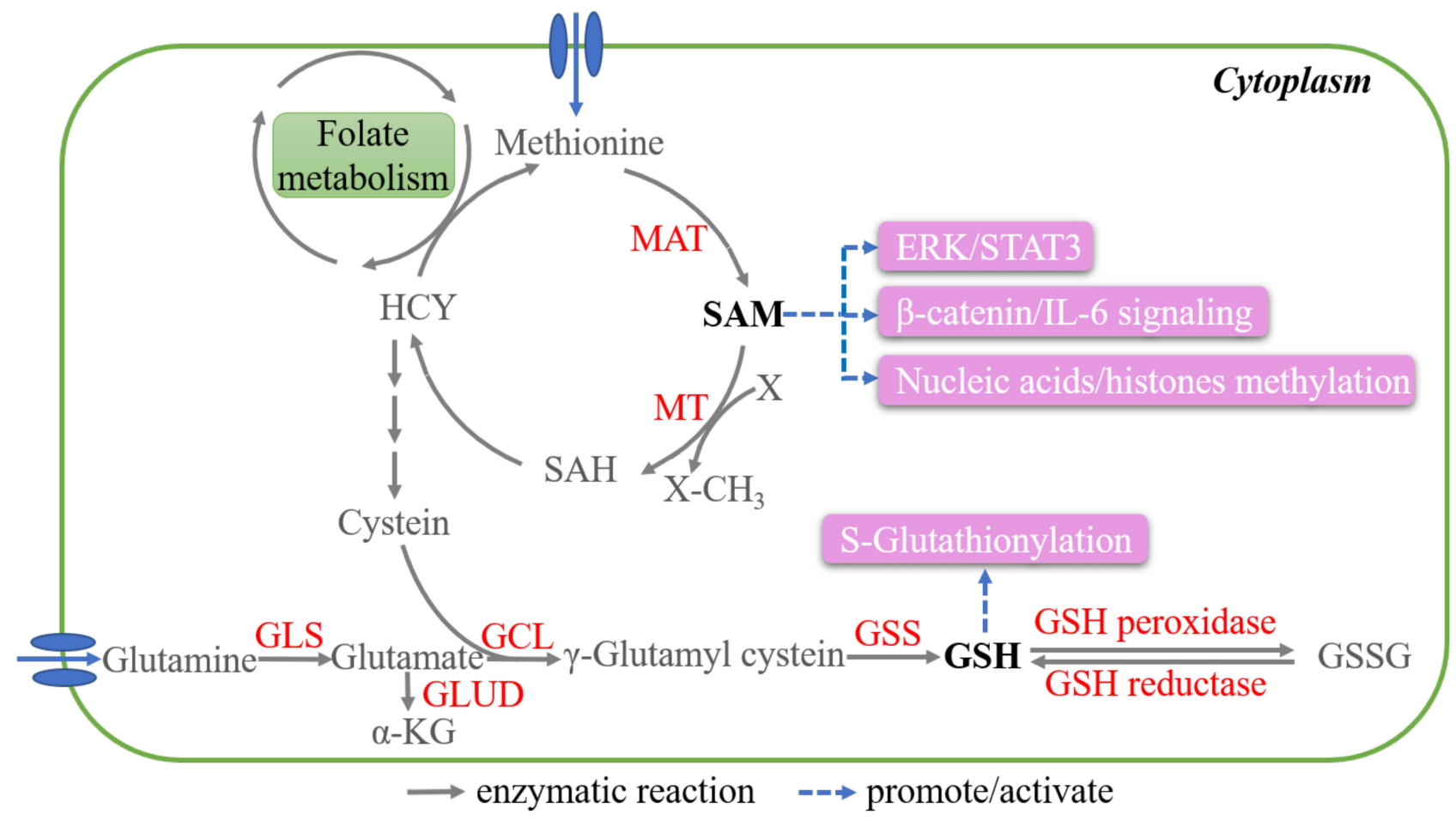

Figure 4 Key metabolites in methionine and glutamine metabolism. The metabolic reactions closely related to SAM and GSH production are shown. SAM is a universal methyl donor and primarily regulates methylation. GSH mainly modify glutathionylation through binding to the cysteine residues of proteins.

Abbreviations: GSH, glutathione; MAT, adenosyltransferase; MT, methyltransferases; SAM, s-adenosyl-methionine; SAH, s-adenosyl-homocysteine; HCY, homocysteine; GLS, glutaminases; GCL, glutamate cysteine ligase; GSS, GSH synthetase.

(3-HK) by kynurenine 3-monooxygenase (KMO), to anthranilic acid (AA) by kynureninase (KYNU), and to kynurenic acid (KA) by kynurenine aminotransferases (KATI-KATIII). After further series of enzymic reactions, multiple biologically active acids are produced, such as 3-hydroxyanthranilic acid (3-HAA), quinolinic acid (QA), picolinic acid (PA), etc. In the end of the KP, NAD+ is generated, which is an important redox cofactor ${ }^{137,138}$ (Figure 5).

\section{Kyn and KA}

Both Kyn and KA are potent agonists for the human aryl hydrocarbon receptor (AhR), ${ }^{139}$ which has extensive roles in carcinogenesis. ${ }^{140}$ Thus, Kyn and KA have potential procarcinogenic effects in cancer. Kyn is significantly elevated in colon cancer cells and promotes the proliferation through activating the AhR. ${ }^{141}$ AhR blockade induces by Kyn could also interrupt the interplay between Tregs and tumorassociated macrophages, which is associated with the resistance to immune checkpoint inhibitors. ${ }^{142}$ DiNatale et al reported that KA activated $\mathrm{AhR}$ and subsequently induced IL-6 production in primary human hepatocytes ${ }^{143}$ (Figure 5).

KA also works as the ligand of other receptors, including glutamate receptors, $\alpha-7$ nicotinic acetylcholine receptor ( $\alpha-7 \mathrm{nAChR})$, and G-protein coupled receptor 35 (GPR35). ${ }^{144}$ As antagonist for endogenous glutamate receptors, KA reverses the promotion effect of glutamate on glioma T98G cell proliferation, and enhances the antiproliferative effect of glutamate receptor antagonists MK801 and GYKI 52466 ${ }^{145}$ (Figure 5). However, the anticancer potential of KA through binding to $\alpha-7 \mathrm{nAChR}$ and GPR35 warrants further study.

\section{Conclusions and Future Perspectives}

Metabolites are multifaceted in cancer cells, exerting metabolic as well as extra-metabolic functions. The comprehensive deciphering of these functions holds immense potential for developing new classes of therapeutics. Multiple intermediates exert extra-metabolic effects on processes such as epigenetic modifications, PTMs, and signaling transduction.

As they are highly heterogeneous, tumors have distinct metabolic signatures, and identifying tumorspecific biomarkers has the potential to improve precise cancer diagnosis. Additionally, there is ample evidence to support the anti-tumor efficacy of targeting this 


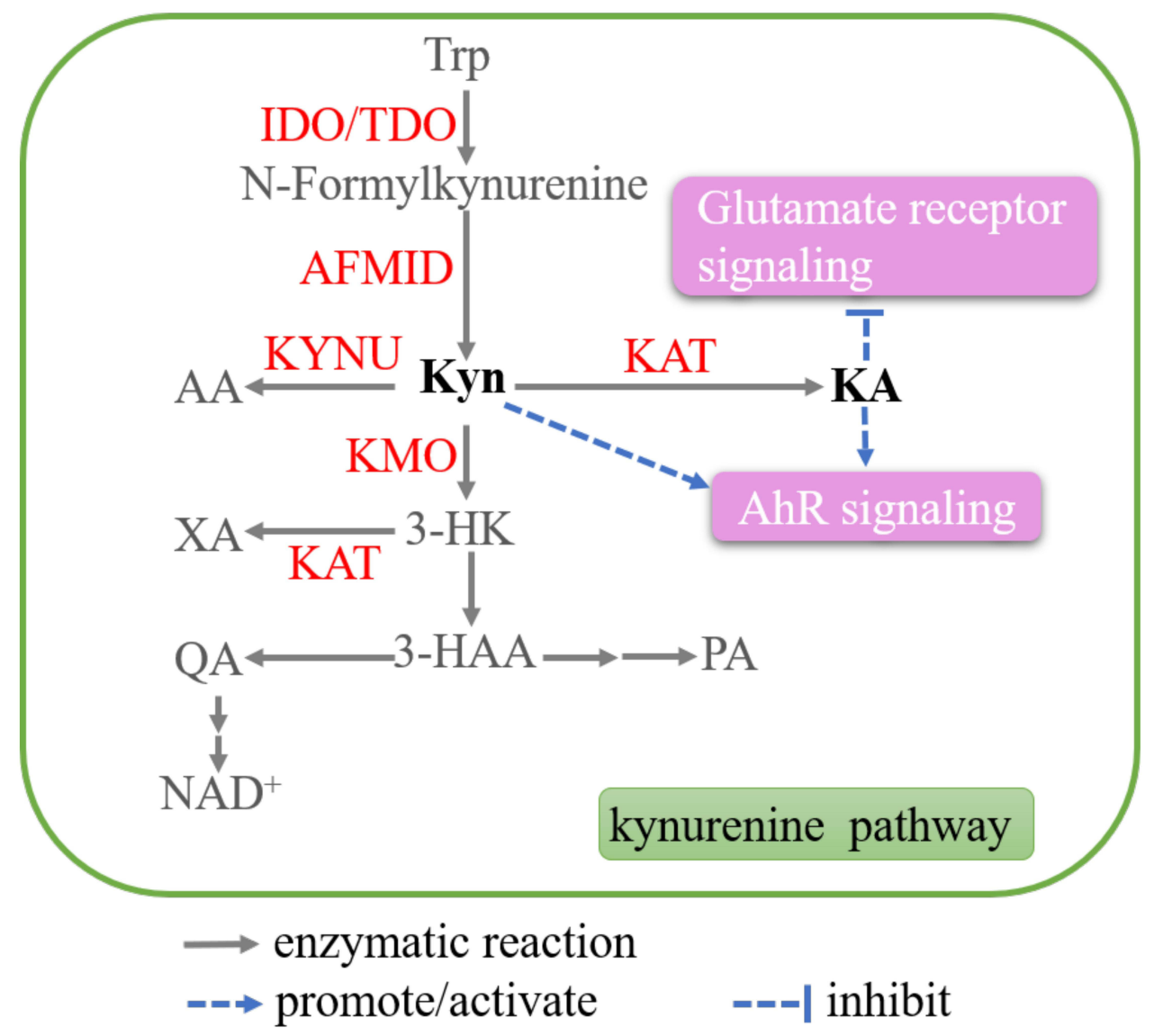

Figure 5 Key metabolites in the tryptophan (Trp) metabolism. The enzymatic reactions in kynurenine (Kyn) pathway (KP) are shown. Kyn and KA work as signal messengers, which are highlighted.

Abbreviations: Trp, tryptophan; Kyn, kynurenine; KP, Kyn pathway; IDOI, indoleamine-2,3-dioxygenase I (IDOI); TDO, tryptophan-2,3-dioxygenase; AFMID, kynurenine formamidase; 3-HK, 3-hydroxykynurenine (3-HK); KMO, kynurenine 3-monooxygenase; AA, anthranilic acid; KYNU, kynureninase (KYNU); KA, kynurenic acid; KAT, kynurenine aminotransferases; 3-HAA, 3-hydroxyanthranilic acid; QA, quinolinic acid; PA, picolinic acid.

metabolic vulnerability alone or in combination. Notably, metabolic pathways are intertwined and largely overlap. A complete blockade may cause active compensatory supply, impairing the inhibitory effects, highlighting the importance of monitoring metabolite dynamics and moderate intervention.

What we have described here is merely the tip of the iceberg, providing the impetus for further investigation. Studies are needed to uncover how metabolites affect the expression of specific genes and signaling pathways in more detail. Furthermore, metabolites exist both outside and inside different cellular compartments, and it would be of interest to explore how metabolite transportation and localization are regulated. It is likely that additional extra-metabolic functions of metabolites will be identified in the near future, which will have far-reaching implications for the understanding of tumor biology and improving translational clinical approaches.

\section{Abbreviations}

1,3-BPG, 1,3-bisphosphoglycerate; 2-HG, 2-hydroxyglutarate; 2-PG, 2-phosphoglycerate; 3-OHB, 3-hydroxybutyrate; 3-PG, 3-phosphoglycerate; 6-PG, 6-phosphogluconate; AcAc-CoA, acetoacetyl-CoA; Ac-CoA, acetyl-CoA; ACL, ATP citrate lyase; ACSS, ac-CoA synthetase; AhR, aryl hydrocarbon receptor; D2HGDH, D-2-hydroxyglutarate dehydrogenase; EMT, epithelial-to-mesenchymal transition; FABP5, fatty acid-binding protein 5; FH, fumarate hydratase; G6P, glucose-6-phosphate; G6PD, glucose-6-phosphate dehydrogenase; GA3P, glyceraldehyde-3-phosphate; GAPDH, glyceraldehyde 3-phosphate dehydrogenase; GCL, glutamate cysteine ligase; GLS, glutaminases; GLUD, glutamate dehydrogenase; GPR, G-protein coupled receptors; GSH, glutathione; GSS, GSH synthetase; HIF1 $\alpha$, hypoxia-inducible factor 1-alpha; HMGCL, 3-hydroxy-3-methylglutaryl-CoA lyase; HMG-CoA, 3-hydroxy-3-methylglutaryl-CoA; HMGCS, 3-hydroxy3-methylglutaryl-CoA synthase; ICL, isocitrate lyase; IDH, 
isocitrate dehydrogenase; Kbhb, lysine $\beta$ hydroxybutyrylation; KDHs, ketoacid dehydrogenases; L2HGDH, L-2-hydroxyglutarate dehydrogenase; KP, kynurenine (Kyn) pathway; KYNU, kynureninase; LCFA, long chain fatty acids; LDH, lactate dehydrogenase; LDHA, lactate dehydrogenase A; MAT2A, methionine adenosyltransferase 2A; MCT1, monocarboxylate transporters; $\mathrm{MDH}$, malate dehydrogenase; MeS, metabolite-sensing module; MeSr, metabolite sensor-mediated signaling; MTs, methyltransferases; NF- $\mathrm{KB}$, nuclear factor $\mathrm{\kappa B}$; $\mathrm{PDH}$, pyruvate dehydrogenase; PEP, phosphoenolpyruvate; PGAM, phosphoglycerate mutase; PGD, phosphogluconate dehydrogenase; PGLS, 6-phosphogluconolactonase; PHD, prolyl hydroxylase domain; PHGDH, phosphoglycerate dehydrogenase; $\mathrm{PPAR} \beta / \delta$, peroxisome proliferator-activated receptor $\beta / \delta$; PPP, pentose phosphate pathway; PTM, posttranscriptional modifications; R-5-P, ribose-5-phosphate; Ru-5-P, ribulose-5-phosphate; SAH, S-adenosylhomocysteine; SAM, S-adenosyl-methionine; SC, sensing by conjugating; SDH, succinate dehydrogenase; TCA cycle, tricarboxylic acid cycle; $\delta$-6-PGL, $\delta$ 6-phosphogluconolactone.

\section{Author Contributions}

All authors contributed to data analysis, drafting or revising the article, have agreed on the journal to which the article will be submitted, gave final approval of the version to be published, and agree to be accountable for all aspects of the work.

\section{Funding}

This research was funded by the National Natural Science Foundation of China (81800174) and the Natural Science Foundation of Hunan Province, China (2020JJ5927).

\section{Disclosure}

The authors report no conflicts of interest in this work.

\section{References}

1. Cairns RA, Harris IS, Mak TW. Regulation of cancer cell metabolism. Nat Rev Cancer. 2011;11(2):85-95. doi:10.1038/nrc2981

2. Lau AN, Vander Heiden MG. Metabolism in the tumor microenvironment. Ann Rev Cancer Biol. 2020;4(1):17-40. doi:10.1146/annurev-cancerbio-030419-033333

3. Phan LM, Yeung SC, Lee MH. Cancer metabolic reprogramming: importance, main features, and potentials for precise targeted anti-cancer therapies. Cancer Biol Med. 2014;11(1):1-19.

4. Yoshida GJ. Metabolic reprogramming: the emerging concept and associated therapeutic strategies. J Exp Clin Cancer Res. 2015;34 (1):111. doi:10.1186/s13046-015-0221-y
5. Sullivan LB, Gui DY, Vander Heiden MG. Altered metabolite levels in cancer: implications for tumour biology and cancer therapy. Nat Rev Cancer. 2016;16(11):680-693. doi:10.1038/ nrc. 2016.85

6. Gillies RJ, Robey I, Gatenby RA. Causes and consequences of increased glucose metabolism of cancers. J Nucl Med. 2008;49 (Suppl 2):24s-42s. doi:10.2967/jnumed.107.047258

7. King A, Selak MA, Gottlieb E. Succinate dehydrogenase and fumarate hydratase: linking mitochondrial dysfunction and cancer. Oncogene. 2006;25(34):4675-4682. doi:10.1038/sj. onc. 1209594

8. Ward PS, Patel J, Wise DR, et al. The common feature of leukemia-associated IDH1 and IDH2 mutations is a neomorphic enzyme activity converting alpha-ketoglutarate to 2-hydroxyglutarate. Cancer Cell. 2010;17(3):225-234. doi:10.1016/ j.ccr.2010.01.020

9. Yang M, Soga T, Pollard PJ. Oncometabolites: linking altered metabolism with cancer. $J$ Clin Invest. 2013;123(9):3652-3658. doi:10.1172/JCI67228

10. Nalbantoglu S, Karadag A. Metabolomics bridging proteomics along metabolites/oncometabolites and protein modifications: paving the way toward integrative multiomics. J Pharm Biomed Anal. 2021;199:114031.

11. Kinnaird A, Zhao S, Wellen KE, Michelakis ED. Metabolic control of epigenetics in cancer. Nat Rev Cancer. 2016;16 (11):694-707. doi:10.1038/nrc.2016.82

12. Stram AR, Payne RM. Post-translational modifications in mitochondria: protein signaling in the powerhouse. Cell Mol Life Sci. 2016;73(21):4063-4073. doi:10.1007/s00018-016-2280-4

13. Wang YP, Lei QY. Metabolite sensing and signaling in cell metabolism. Signal Transduct Target Ther. 2018;3(1):30. doi:10.1038/s41392-018-0024-7

14. Alfarouk KO, Verduzco D, Rauch $\mathrm{C}$, et al. Glycolysis, tumor metabolism, cancer growth and dissemination. A new pH-based etiopathogenic perspective and therapeutic approach to an old cancer question. Oncoscience. 2014;1(12):777-802. doi:10.18 632/oncoscience. 109

15. Moellering RE, Cravatt BF. Functional lysine modification by an intrinsically reactive primary glycolytic metabolite. Science. 2013;341(6145):549-553. doi:10.1126/science.1238 327

16. Oslund RC, Su X, Haugbro M, et al. Bisphosphoglycerate mutase controls serine pathway flux via 3-phosphoglycerate. Nat Chem Biol. 2017;13(10):1081-1087. doi:10.1038/nchembio.2453

17. Hitosugi T, Zhou L, Elf S, et al. Phosphoglycerate mutase 1 coordinates glycolysis and biosynthesis to promote tumor growth. Cancer Cell. 2012;22(5):585-600. doi:10.1016/j.ccr.20 12.09.020

18. Ho PC, Bihuniak JD, Macintyre AN, et al. Phosphoenolpyruvate is a metabolic checkpoint of anti-tumor T cell responses. Cell. 2015;162(6):1217-1228. doi:10.1016/j.cell.2015.08.012

19. Moreno-Felici J, Hyroššová P, Aragó M, et al. Phosphoenolpyruvate from glycolysis and PEPCK regulate cancer cell fate by altering cytosolic $\mathrm{Ca}(2)$. Cells. 2019;9(1):18. doi:10.3390/cells9010018

20. San-Millán I, Brooks GA. Reexamining cancer metabolism: lactate production for carcinogenesis could be the purpose and explanation of the Warburg effect. Carcinogenesis. 2017;38 (2):119-133.

21. Ippolito L, Morandi A, Giannoni E, Chiarugi P. Lactate: a metabolic driver in the tumour landscape. Trends Biochem Sci. 2019;44(2):153-166. doi:10.1016/j.tibs.2018.10.011

22. De Saedeleer CJ, Copetti T, Porporato PE, Verrax J, Feron O, Sonveaux P. Lactate activates HIF-1 in oxidative but not in Warburg-phenotype human tumor cells. PLoS One. 2012;7(10): e46571. doi:10.1371/journal.pone.0046571 
23. Végran F, Boidot R, Michiels C, Sonveaux P, Feron O. Lactate influx through the endothelial cell monocarboxylate transporter MCT1 supports an NF-kB/IL-8 pathway that drives tumor angiogenesis. Cancer Res. 2011;71(7):2550-2560. doi:10.1158/00085472.CAN-10-2828

24. Lee DC, Sohn HA, Park ZY, et al. A lactate-induced response to hypoxia. Cell. 2015;161(3):595-609. doi:10.1016/j.cell.2015.03. 011

25. Colegio OR, Chu NQ, Szabo AL, et al. Functional polarization of tumour-associated macrophages by tumour-derived lactic acid. Nature. 2014;513(7519):559-563. doi:10.1038/nature13490

26. Kes MMG, Van den Bossche J, Griffioen AW, Huijbers EJM. Oncometabolites lactate and succinate drive pro-angiogenic macrophage response in tumors. Biochim Biophys Acta Rev Cancer. 2020;1874(2):188427. doi:10.1016/j.bbcan.2020.188427

27. Mu X, Shi W, Xu Y, et al. Tumor-derived lactate induces M2 macrophage polarization via the activation of the ERK/STAT3 signaling pathway in breast cancer. Cell Cycle. 2018;17 (4):428-438. doi:10.1080/15384101.2018.1444305

28. Roland CL, Arumugam T, Deng D, et al. Cell surface lactate receptor GPR81 is crucial for cancer cell survival. Cancer Res. 2014;74(18):5301-5310. doi:10.1158/0008-5472.CAN-14-0319

29. Feng J, Yang H, Zhang Y, et al. Tumor cell-derived lactate induces TAZ-dependent upregulation of PD-L1 through GPR81 in human lung cancer cells. Oncogene. 2017;36(42):5829-5839. doi:10.1038/onc.2017.188

30. Brown TP, Ganapathy V. Lactate/GPR81 signaling and proton motive force in cancer: role in angiogenesis, immune escape, nutrition, and Warburg phenomenon. Pharmacol Ther. 2020;206:107451. doi:10.1016/j.pharmthera.2019.107451

31. Yang K, Xu J, Fan M, et al. Lactate suppresses macrophage proinflammatory response to LPS stimulation by inhibition of YAP and NF- $\mathrm{KB}$ activation via GPR81-mediated signaling. Front Immunol. 2020;11:587913. doi:10.3389/fimmu.2020.587913

32. Zhang W, Wang G, Xu ZG, et al. Lactate is a natural suppressor of RLR signaling by targeting MAVS. Cell. 2019;178(1):176189.e115. doi:10.1016/j.cell.2019.05.003

33. Latham T, Mackay L, Sproul D, et al. Lactate, a product of glycolytic metabolism, inhibits histone deacetylase activity and promotes changes in gene expression. Nucleic Acids Res. 2012;40 (11):4794-4803. doi:10.1093/nar/gks066

34. Zhang D, Tang Z, Huang H, et al. Metabolic regulation of gene expression by histone lactylation. Nature. 2019;574 (7779):575-580. doi:10.1038/s41586-019-1678-1

35. Patra KC, Hay N. The pentose phosphate pathway and cancer. Trends Biochem Sci. 2014;39(8):347-354. doi:10.1016/j. tibs.2014.06.005

36. Shackelford DB, Shaw RJ. The LKB1-AMPK pathway: metabolism and growth control in tumour suppression. Nat Rev Cancer. 2009;9(8):563-575. doi:10.1038/nrc2676

37. Park S, Scheffler TL, Rossie SS, Gerrard DE. AMPK activity is regulated by calcium-mediated protein phosphatase $2 \mathrm{~A}$ activity. Cell Calcium. 2013;53(3):217-223. doi:10.1016/j.ceca.2012.12. 001

38. Lin R, Elf S, Shan C, et al. 6-Phosphogluconate dehydrogenase links oxidative PPP, lipogenesis and tumour growth by inhibiting LKB1-AMPK signalling. Nat Cell Biol. 2015;17(11):1484-1496. doi: $10.1038 / \mathrm{ncb} 3255$

39. Gao X, Zhao L, Liu S, et al. $\gamma$-6-Phosphogluconolactone, a byproduct of the oxidative pentose phosphate pathway, contributes to AMPK activation through inhibition of PP2A. Mol Cell. 2019;76(6):857-871.e859. doi:10.1016/j.molcel.2019.09. 007

40. Anderson NM, Mucka P, Kern JG, Feng H. The emerging role and targetability of the TCA cycle in cancer metabolism. Protein Cell. 2018;9(2):216-237. doi:10.1007/s13238-017-0451-1
41. Dang L, White DW, Gross S, et al. Cancer-associated IDH1 mutations produce 2-hydroxyglutarate. Nature. 2009;462 (7274):739-744. doi:10.1038/nature08617

42. Yan H, Parsons DW, Jin G, et al. IDH1 and IDH2 mutations in gliomas. $N$ Engl J Med. 2009;360(8):765-773. doi:10.1056/ NEJMoa0808710

43. Mardis ER, Ding L, Dooling DJ, et al. Recurring mutations found by sequencing an acute myeloid leukemia genome. $N$ Engl $J$ Med. 2009;361(11):1058-1066. doi:10.1056/NEJMoa0903840

44. Parsons DW, Jones S, Zhang X, et al. An integrated genomic analysis of human glioblastoma multiforme. Science. 2008;321 (5897):1807-1812. doi:10.1126/science.1164382

45. Yang H, Ye D, Guan KL, Xiong Y. IDH1 and IDH2 mutations in tumorigenesis: mechanistic insights and clinical perspectives. Clin Cancer Res. 2012;18(20):5562-5571. doi:10.1158/10780432.CCR-12-1773

46. Dang $\mathrm{L}, \mathrm{Su} \mathrm{SM}$. Isocitrate dehydrogenase mutation and (R)-2-hydroxyglutarate: from basic discovery to therapeutics development. Annu Rev Biochem. 2017;86(1):305-331. doi:10.1146/annurev-biochem-061516-044732

47. Fan J, Teng X, Liu L, et al. Human phosphoglycerate dehydrogenase produces the oncometabolite D-2-hydroxyglutarate. ACS Chem Biol. 2015;10(2):510-516. doi:10.1021/cb500683c

48. Rzem R, Vincent MF, Van Schaftingen E, Veiga-da-cunha M. L-2-hydroxyglutaric aciduria, a defect of metabolite repair. $J$ Inherit Metab Dis. 2007;30(5):681-689. doi:10.1007/s10545007-0487-0

49. Intlekofer AM, Dematteo RG, Venneti S, et al. Hypoxia induces production of L-2-hydroxyglutarate. Cell Metab. 2015;22 (2):304-311.

50. Struys EA, Salomons GS, Achouri Y, et al. Mutations in the D-2-hydroxyglutarate dehydrogenase gene cause D-2-hydroxyglutaric aciduria. Am J Hum Genet. 2005;76 (2):358-360. doi:10.1086/427890

51. Achouri Y, Noël G, Vertommen D, Rider MH, Veiga-da-cunha M, Van Schaftingen E. Identification of a dehydrogenase acting on D-2-hydroxyglutarate. Biochem J. 2004;381(Pt 1):35-42. doi:10.1042/BJ20031933

52. Rzem R, Veiga-da-cunha M, Noël G, et al. A gene encoding a putative FAD-dependent L-2-hydroxyglutarate dehydrogenase is mutated in L-2-hydroxyglutaric aciduria. Proc Natl Acad Sci U S A. 2004;101(48):16849-16854. doi:10.1073/pnas.040484 0101

53. Xu W, Yang H, Liu Y, et al. Oncometabolite 2-hydroxyglutarate is a competitive inhibitor of $\alpha$-ketoglutarate-dependent dioxygenases. Cancer Cell. 2011;19(1):17-30. doi:10.1016/j.ccr.2010. 12.014

54. Chowdhury R, Yeoh KK, Tian YM, et al. The oncometabolite 2-hydroxyglutarate inhibits histone lysine demethylases. EMBO Rep. 2011;12(5):463-469. doi:10.1038/embor.2011.43

55. Losman JA, Koivunen P, Kaelin WG Jr. 2-Oxoglutaratedependent dioxygenases in cancer. Nat Rev Cancer. 2020;20 (12):710-726.

56. Shi Y, Whetstine JR. Dynamic regulation of histone lysine methylation by demethylases. Mol Cell. 2007;25(1):1-14. doi:10.1016/j. molcel.2006.12.010

57. Lu C, Ward PS, Kapoor GS, et al. IDH mutation impairs histone demethylation and results in a block to cell differentiation. Nature. 2012;483(7390):474-478. doi:10.1038/nature10860

58. Carbonneau M, Lalonde L, Lalonde M-E. The oncometabolite 2-hydroxyglutarate activates the mTOR signalling pathway. Nat Commun. 2016;7(1):12700. doi:10.1038/ncomms 12700

59. Tahiliani M, Koh KP, Shen Y, et al. Conversion of 5-methylcytosine to 5-hydroxymethylcytosine in mammalian DNA by MLL partner TET1. Science. 2009;324(5929):930-935. doi:10.1126/science. 1170116 
60. Figueroa ME, Abdel-Wahab O, Lu C, et al. Leukemic IDH1 and IDH2 mutations result in a hypermethylation phenotype, disrupt TET2 function, and impair hematopoietic differentiation. Cancer Cell. 2010;18(6):553-567. doi:10.1016/j.ccr.2010.11.015

61. Zhao S, Lin Y, Xu W, et al. Glioma-derived mutations in IDH1 dominantly inhibit IDH1 catalytic activity and induce HIF-1alpha. Science. 2009;324(5924):261-265. doi:10.1126/ science. 1170944

62. Tarhonskaya H, Rydzik AM, Leung IK, et al. Non-enzymatic chemistry enables 2-hydroxyglutarate-mediated activation of 2-oxoglutarate oxygenases. Nat Commun. 2014;5(1):3423. doi: $10.1038 /$ ncomms 4423

63. Keith B, Johnson RS, Simon MC. HIF1 $\alpha$ and HIF2 $\alpha$ : sibling rivalry in hypoxic tumour growth and progression. Nat Rev Cancer. 2011;12(1):9-22. doi:10.1038/nrc3183

64. Wang P, Wu J, Ma S, et al. Oncometabolite D-2-hydroxyglutarate inhibits ALKBH DNA repair enzymes and sensitizes IDH mutant cells to alkylating agents. Cell Rep. 2015;13(11):2353-2361. doi:10.1016/j.celrep.2015.11.029

65. Gill AJ. Succinate dehydrogenase (SDH)-deficient neoplasia. Histopathology. 2018;72(1):106-116. doi:10.1111/his.13277

66. Zhao T, Mu X, You Q. Succinate: an initiator in tumorigenesis and progression. Oncotarget. 2017;8(32):53819-53828. doi:10.18632/oncotarget.17734

67. Rasola A, Neckers L, Picard D. Mitochondrial oxidative phosphorylation TRAP(1)ped in tumor cells. Trends Cell Biol. 2014;24(8):455-463. doi:10.1016/j.tcb.2014.03.005

68. Xiao $\mathrm{M}$, Yang $\mathrm{H}, \mathrm{Xu} \mathrm{W}$, et al. Inhibition of $\alpha-\mathrm{KG}$-dependent histone and DNA demethylases by fumarate and succinate that are accumulated in mutations of $\mathrm{FH}$ and SDH tumor suppressors. Genes Dev. 2012;26(12):1326-1338. doi:10.1101/gad.191056.112

69. Letouzé E, Martinelli C, Loriot C, et al. SDH mutations establish a hypermethylator phenotype in paraganglioma. Cancer Cell. 2013;23(6):739-752. doi:10.1016/j.ccr.2013.04.018

70. Loriot C, Burnichon N, Gadessaud N, et al. Epithelial to mesenchymal transition is activated in metastatic pheochromocytomas and paragangliomas caused by SDHB gene mutations. $J$ Clin Endocrinol Metab. 2012;97(6):E954-962. doi:10.1210/ jc. 2011-3437

71. Loriot C, Domingues M, Berger A, et al. Deciphering the molecular basis of invasiveness in Sdhb-deficient cells. Oncotarget. 2015;6(32):32955-32965. doi:10.18632/oncotarget.5106

72. Rapizzi E, Ercolino T, Fucci R, et al. Succinate dehydrogenase subunit B mutations modify human neuroblastoma cell metabolism and proliferation. Horm Cancer. 2014;5(3):174-184. doi:10.1007/s12672-014-0172-3

73. Hoekstra AS, de Graaff MA, Briaire-de Bruijn IH, et al. Inactivation of $\mathrm{SDH}$ and $\mathrm{FH}$ cause loss of $5 \mathrm{hmC}$ and increased H3K9me3 in paraganglioma/pheochromocytoma and smooth muscle tumors. Oncotarget. 2015;6(36):38777-38788. doi:10. 18632/oncotarget.6091

74. Selak MA, Armour SM, MacKenzie ED, et al. Succinate links TCA cycle dysfunction to oncogenesis by inhibiting HIF-alpha prolyl hydroxylase. Cancer Cell. 2005;7(1):77-85. doi:10.1016/j. ccr.2004.11.022

75. Tretter L, Patocs A, Chinopoulos C. Succinate, an intermediate in metabolism, signal transduction, ROS, hypoxia, and tumorigenesis. Biochim Biophys Acta. 2016;1857(8):1086-1101. doi:10.1016/j.bbabio.2016.03.012

76. Smestad J, Erber L, Chen Y, Maher LJ 3rd. Chromatin succinylation correlates with active gene expression and is perturbed by defective TCA cycle metabolism. iScience. 2018;2:63-75. doi:10.1016/j.isci.2018.03.012

77. Dalla Pozza E, Dando I, Pacchiana R, et al. Regulation of succinate dehydrogenase and role of succinate in cancer. Semin Cell Dev Biol. 2020;98:4-14. doi:10.1016/j.semcdb.2019.04.013
78. Liu C, Liu Y, Chen L, et al. Quantitative proteome and lysine succinylome analyses provide insights into metabolic regulation in breast cancer. Breast Cancer. 2019;26(1):93-105. doi:10.1007/ s12282-018-0893-1

79. Li X, Zhang C, Zhao $\mathrm{T}$, et al. Lysine-222 succinylation reduces lysosomal degradation of lactate dehydrogenase a and is increased in gastric cancer. J Exp Clin Cancer Res. 2020;39(1):172. doi:10.1186/s13046-020-01681-0

80. Mu X, Zhao T, Xu C, et al. Oncometabolite succinate promotes angiogenesis by upregulating VEGF expression through GPR91-mediated STAT3 and ERK activation. Oncotarget. 2017;8(8):13174-13185. doi:10.18632/oncotarget.14485

81. Wu JY, Huang TW, Hsieh YT, et al. Cancer-derived succinate promotes macrophage polarization and cancer metastasis via succinate receptor. Mol Cell. 2020;77(2):213-227.e215. doi:10.1016/ j.molcel.2019.10.023

82. Tomlinson IP, Alam NA, Rowan AJ, et al. Germline mutations in FH predispose to dominantly inherited uterine fibroids, skin leiomyomata and papillary renal cell cancer. Nat Genet. 2002;30 (4):406-410.

83. Bardella C, El-Bahrawy M, Frizzell N, et al. Aberrant succination of proteins in fumarate hydratase-deficient mice and HLRCC patients is a robust biomarker of mutation status. J Pathol. 2011;225(1):4-11. doi:10.1002/path.2932

84. Blatnik M, Frizzell N, Thorpe SR, Baynes JW. Inactivation of glyceraldehyde-3-phosphate dehydrogenase by fumarate in diabetes: formation of S-(2-succinyl)cysteine, a novel chemical modification of protein and possible biomarker of mitochondrial stress. Diabetes. 2008;57(1):41-49. doi:10.2337/db07-0838

85. Frizzell N, Rajesh M, Jepson MJ, et al. Succination of thiol groups in adipose tissue proteins in diabetes: succination inhibits polymerization and secretion of adiponectin. $J$ Biol Chem. 2009;284(38):25772-25781. doi:10.1074/jbc.M109.019257

86. Kinch L, Grishin NV, Brugarolas J. Succination of Keap1 and activation of Nrf2-dependent antioxidant pathways in FH-deficient papillary renal cell carcinoma type 2. Cancer Cell. 2011;20(4):418-420. doi:10.1016/j.ccr.2011.10.005

87. Adam J, Hatipoglu E, O'Flaherty L, et al. Renal cyst formation in Fh1-deficient mice is independent of the Hif/Phd pathway: roles for fumarate in KEAP1 succination and Nrf2 signaling. Cancer Cell. 2011;20(4):524-537. doi:10.1016/j.ccr.2011.09.006

88. Sullivan LB, Martinez-Garcia E, Nguyen $H$, et al. The proto-oncometabolite fumarate binds glutathione to amplify ROS-dependent signaling. Mol Cell. 2013;51(2):236-248. doi:10.1016/j.molcel.2013.05.003

89. Zheng L, Cardaci S, Jerby L, et al. Fumarate induces redox-dependent senescence by modifying glutathione metabolism. Nat Commun. 2015;6(1):6001. doi:10.1038/ ncomms7001

90. Yoshii Y, Furukawa T, Saga T, Fujibayashi Y. Acetate/acetyl-CoA metabolism associated with cancer fatty acid synthesis: overview and application. Cancer Lett. 2015;356(2Pt A):211-216. doi:10.1016/j.canlet.2014.02.019

91. Yoshii Y, Waki A, Furukawa T, et al. Tumor uptake of radiolabeled acetate reflects the expression of cytosolic acetyl-CoA synthetase: implications for the mechanism of acetate PET. Nucl Med Biol. 2009;36(7):771-777. doi:10.1016/j.nucmedbio.2009. 05.006

92. Bauer DE, Hatzivassiliou G, Zhao F, Andreadis C, Thompson CB. ATP citrate lyase is an important component of cell growth and transformation. Oncogene. 2005;24(41):63 14-6322. doi:10.1038/sj.onc. 1208773

93. Schug ZT, Peck B, Jones DT, et al. Acetyl-CoA synthetase 2 promotes acetate utilization and maintains cancer cell growth under metabolic stress. Cancer Cell. 2015;27(1):57-71. doi:10. 1016/j.ccell.2014.12.002 
94. Metallo CM, Gameiro PA, Bell EL, et al. Reductive glutamine metabolism by IDH1 mediates lipogenesis under hypoxia. Nature. 2011;481(7381):380-384. doi:10.1038/nature10602

95. Lee JV, Carrer A, Shah S, et al. Akt-dependent metabolic reprogramming regulates tumor cell histone acetylation. Cell Metab. 2014;20(2):306-319. doi:10.1016/j.cmet.2014.06.004

96. Trefely S, Lovell CD, Snyder NW, Wellen KE. Compartmentalised acyl-CoA metabolism and roles in chromatin regulation. Mol Metab. 2020;38:100941. doi:10.1016/j. molmet.2020.01.005

97. McDonnell E, Crown SB, Fox DB, et al. Lipids reprogram metabolism to become a major carbon source for histone acetylation. Cell Rep. 2016;17(6):1463-1472. doi:10.1016/j. celrep.2016.10.012

98. Carrer A, Trefely S, Zhao S, et al. Acetyl-CoA metabolism supports multistep pancreatic tumorigenesis. Cancer Discov. 2019;9(3):416-435. doi:10.1158/2159-8290.CD-18-0567

99. Zheng ZQ, Li ZX, Guan JL, et al. Long noncoding RNA TINCR-mediated regulation of acetyl-CoA metabolism promotes nasopharyngeal carcinoma progression and chemoresistance. Cancer Res. 2020;80(23):5174-5188. doi:10.1158/0008-5472.CAN-19-3626

100. Gao X, Lin SH, Ren F, et al. Acetate functions as an epigenetic metabolite to promote lipid synthesis under hypoxia. Nat Commun. 2016;7(1):11960. doi:10.1038/ncomms11960

101. Lin R, Tao R, Gao X, et al. Acetylation stabilizes ATP-citrate lyase to promote lipid biosynthesis and tumor growth. Mol Cell. 2013;51(4):506-518. doi:10.1016/j.molcel.2013.07.002

102. Chen D, Xia S, Zhang R, et al. Lysine acetylation restricts mutant IDH2 activity to optimize transformation in AML cells. Mol Cell. 2021;S1097-2765(21)00507-4. doi:10.1016/j.molcel.2021.06.027

103. Bose S, Ramesh V, Locasale JW. Acetate metabolism in physiology, cancer, and beyond. Trends Cell Biol. 2019;29(9):695-703. doi:10.1016/j.tcb.2019.05.005

104. Schug ZT, Vande Voorde J, Gottlieb E. The metabolic fate of acetate in cancer. Nat Rev Cancer. 2016;16(11):708-717. doi:10.1038/nrc. 2016.87

105. Hatanaka H, Tsukui M, Takada S, et al. Identification of transforming activity of free fatty acid receptor 2 by retroviral expression screening. Cancer Sci. 2010;101(1):54-59. doi:10.1111/ j.1349-7006.2009.01348.x

106. Yonezawa T, Kobayashi Y, Obara Y. Short-chain fatty acids induce acute phosphorylation of the p38 mitogen-activated protein kinase/heat shock protein 27 pathway via GPR43 in the MCF-7 human breast cancer cell line. Cell Signal. 2007;19 (1):185-193. doi:10.1016/j.cellsig.2006.06.004

107. Levi L, Wang Z, Doud MK, Hazen SL, Noy N. Saturated fatty acids regulate retinoic acid signalling and suppress tumorigenesis by targeting fatty acid-binding protein 5. Nat Commun. 2015;6 (1):8794. doi:10.1038/ncomms9794

108. Armstrong EH, Goswami D, Griffin PR, Noy N, Ortlund EA. Structural basis for ligand regulation of the fatty acid-binding protein 5 , peroxisome proliferator-activated receptor $\beta / \delta$ (FABP5PPAR $\beta / \delta$ ) signaling pathway. $J$ Biol Chem. 2014;289 (21):14941-14954. doi:10.1074/jbc.M113.514646

109. Longo R, Peri C, Cricrì D, et al. Ketogenic diet: a new light shining on old but gold biochemistry. Nutrients. 2019;11 (10):2497. doi:10.3390/nu11102497

110. Abdelmegeed MA, Kim SK, Woodcroft KJ, Novak RF. Acetoacetate activation of extracellular signal-regulated kinase $1 / 2$ and p38 mitogen-activated protein kinase in primary cultured rat hepatocytes: role of oxidative stress. $J$ Pharmacol Exp Ther. 2004;310(2):728-736. doi:10.1124/jpet.104.066522

111. Kang HB, Fan J, Lin R, et al. Metabolic rewiring by oncogenic BRAF V600E links ketogenesis pathway to BRAF-MEK1 signaling. Mol Cell. 2015;59(3):345-358. doi:10.1016/j.molcel. 2015.05.037
112. Zhao L, Fan J, Xia S, et al. HMG-CoA synthase 1 is a synthetic lethal partner of BRAF(V600E) in human cancers. J Biol Chem. 2017;292(24):10142-10152. doi:10.1074/jbc.M117.788778

113. Xia S, Lin R, Jin L, et al. Prevention of dietary-fat-fueled ketogenesis attenuates BRAF V600E tumor growth. Cell Metab. 2017;25(2):358-373. doi:10.1016/j.cmet.2016.12.010

114. Newman JC, Verdin E. $\beta$-hydroxybutyrate: much more than a metabolite. Diabetes Res Clin Pract. 2014;106(2):173-181. doi:10.1016/j.diabres.2014.08.009

115. Newman JC, Verdin E. Ketone bodies as signaling metabolites. Trends Endocrinol Metab. 2014;25(1):42-52. doi:10.1016/j. tem.2013.09.002

116. Moller N. Ketone body, 3-hydroxybutyrate: minor metabolite major medical manifestations. J Clin Endocrinol Metab. 2020;105(9):2884-2892. doi:10.1210/clinem/dgaa370

117. Dabek A, Wojtala M, Pirola L, Balcerczyk A. Modulation of cellular biochemistry, epigenetics and metabolomics by ketone bodies. Implications of the ketogenic diet in the physiology of the organism and pathological states. Nutrients. 2020;12(3):788. doi:10.3390/nu12030788

118. Shimazu T, Hirschey MD, Newman J, et al. Suppression of oxidative stress by $\beta$-hydroxybutyrate, an endogenous histone deacetylase inhibitor. Science. 2013;339(6116):211-214. doi:10. 1126/science. 1227166

119. Xie Z, Zhang D, Chung D, et al. Metabolic regulation of gene expression by histone lysine $\beta$-hydroxybutyrylation. Mol Cell. 2016;62(2):194-206. doi:10.1016/j.molcel.2016.03.036

120. Liu K, Li F, Sun Q, et al. p53 $\beta$-hydroxybutyrylation attenuates p53 activity. Cell Death Dis. 2019;10(3):243. doi:10.1038/ s41419-019-1463-y

121. Ristic B, Bhutia YD, Ganapathy V. Cell-surface G-proteincoupled receptors for tumor-associated metabolites: a direct link to mitochondrial dysfunction in cancer. Biochim Biophys Acta Rev Cancer. 2017;1868(1):246-257. doi:10.1016/j.bbcan.2017. 05.003

122. Sanderson SM, Gao X, Dai Z, Locasale JW. Methionine metabolism in health and cancer: a nexus of diet and precision medicine. Nat Rev Cancer. 2019;19(11):625-637. doi:10.1038/s41568-0190187-8

123. Schmidt T, Leha A, Salinas-Riester G. Treatment of prostate cancer cells with S-adenosylmethionine leads to genome-wide alterations in transcription profiles. Gene. 2016;595(2):161-167. doi:10.1016/j.gene.2016.09.032

124. Mentch SJ, Mehrmohamadi M, Huang L, et al. Histone methylation dynamics and gene regulation occur through the sensing of one-carbon metabolism. Cell Metab. 2015;22(5):861-873. doi:10.1016/j.cmet.2015.08.024

125. Shukeir N, Pakneshan P, Chen G, Szyf M, Rabbani SA. Alteration of the methylation status of tumor-promoting genes decreases prostate cancer cell invasiveness and tumorigenesis in vitro and in vivo. Cancer Res. 2006;66(18):9202-9210. doi:10.1158/00085472.CAN-06-1954

126. Chik F, Machnes Z, Szyf M. Synergistic anti-breast cancer effect of a combined treatment with the methyl donor S-adenosyl methionine and the DNA methylation inhibitor 5-aza-2'deoxycytidine. Carcinogenesis. 2014;35(1):138-144. doi:10.10 93/carcin/bgt284

127. Luo J, Li YN, Wang F, Zhang WM, Geng X. S-adenosylmethionine inhibits the growth of cancer cells by reversing the hypomethylation status of c-myc and $\mathrm{H}$-ras in human gastric cancer and colon cancer. Int J Biol Sci. 2010;6 (7):784-795. doi:10.7150/ijbs.6.784

128. Li TW, Yang H, Peng H, Xia M, Mato JM, Lu SC. Effects of S-adenosylmethionine and methylthioadenosine on inflammation-induced colon cancer in mice. Carcinogenesis. 2012;33(2):427-435. doi:10.1093/carcin/bgr295 
129. Li TW, Peng $\mathrm{H}$, Yang $\mathrm{H}$, et al. S-Adenosylmethionine and methylthioadenosine inhibit $\beta$-catenin signaling by multiple mechanisms in liver and colon cancer. Mol Pharmacol. 2015;87 (1):77-86. doi:10.1124/mol.114.095679

130. Ilisso CP, Sapio L, Delle Cave D, et al. S-Adenosylmethionine affects ERK1/2 and Stat3 pathways and induces apotosis in osteosarcoma cells. J Cell Physiol. 2016;231(2):428-435. doi:10.1002/jcp. 25089

131. Altman BJ, Stine ZE, Dang CV. From Krebs to clinic: glutamine metabolism to cancer therapy. Nat Rev Cancer. 2016;16 (10):619-634. doi:10.1038/nrc.2016.71

132. Bansal A, Simon MC. Glutathione metabolism in cancer progression and treatment resistance. $J$ Cell Biol. 2018;217 (7):2291-2298. doi:10.1083/jcb.201804161

133. Singh S, Khan AR, Gupta AK. Role of glutathione in cancer pathophysiology and therapeutic interventions. $J$ Exp Ther Oncol. 2012;9(4):303-316.

134. Zhang J, Ye ZW, Singh S, Townsend DM, Tew KD. An evolving understanding of the S-glutathionylation cycle in pathways of redox regulation. Free Radic Biol Med. 2018;120:204-216. doi:10.1016/j.freeradbiomed.2018.03.038

135. Tew KD, Manevich Y, Grek C, Xiong Y, Uys J, Townsend DM. The role of glutathione S-transferase $\mathrm{P}$ in signaling pathways and S-glutathionylation in cancer. Free Radic Biol Med. 2011;51 (2):299-313. doi:10.1016/j.freeradbiomed.2011.04.013

136. García-Giménez JL, Òlaso G, Hake SB, et al. Histone h3 glutathionylation in proliferating mammalian cells destabilizes nucleosomal structure. Antioxid Redox Signal. 2013;19 (12):1305-1320. doi:10.1089/ars.2012.5021

137. Platten M, Nollen EAA, Rohrig UF, Fallarino F, Opitz CA. Tryptophan metabolism as a common therapeutic target in cancer, neurodegeneration and beyond. Nat Rev Drug Discov. 2019;18 (5):379-401.
138. Liu XH, Zhai XY. Role of tryptophan metabolism in cancers and therapeutic implications. Biochimie. 2021;182:131-139. doi:10. 1016/j.biochi.2021.01.005

139. Walczak K, Langner E, Makuch-Kocka A, et al. Effect of tryptophan-derived ahr ligands, kynurenine, kynurenic acid and FICZ, on proliferation, cell cycle regulation and cell death of melanoma cells-in vitro studies. Int J Mol Sci. 2020;21 (21):7946. doi:10.3390/ijms21217946

140. Kolluri SK, Jin UH, Safe S. Role of the aryl hydrocarbon receptor in carcinogenesis and potential as an anti-cancer drug target. Arch Toxicol. 2017;91(7):2497-2513. doi:10.1007/s00204-017-1981-2

141. Venkateswaran N, Lafita-Navarro MC, Hao YH, et al. MYC promotes tryptophan uptake and metabolism by the kynurenine pathway in colon cancer. Genes Dev. 2019;33(17-18):1236-1251. doi: $10.1101 / \operatorname{gad} .327056 .119$

142. Campesato LF, Budhu S, Tchaicha J, et al. Blockade of the AHR restricts a Treg-macrophage suppressive axis induced by L-Kynurenine. Nat Commun. 2020;11(1):4011. doi:10.1038/ s41467-020-17750-z

143. DiNatale BC, Murray IA, Schroeder JC, et al. Kynurenic acid is a potent endogenous aryl hydrocarbon receptor ligand that synergistically induces interleukin-6 in the presence of inflammatory signaling. Toxicol Sci. 2010;115(1):89-97. doi:10.1093/toxsci/ $\mathrm{kfq024}$

144. Walczak K, Wnorowski A, Turski WA, Plech T. Kynurenic acid and cancer: facts and controversies. Cell Mol Life Sci. 2020;77 (8):1531-1550. doi:10.1007/s00018-019-03332-w

145. Walczak K, Deneka-Hannemann S, Jarosz B, et al. Kynurenic acid inhibits proliferation and migration of human glioblastoma T98G cells. Pharmacol Rep. 2014;66(1):130-136. doi:10.1016/j. pharep.2013.06.007

\section{Publish your work in this journal}

Cancer Management and Research is an international, peer-reviewed open access journal focusing on cancer research and the optimal use of preventative and integrated treatment interventions to achieve improved outcomes, enhanced survival and quality of life for the cancer patient.
The manuscript management system is completely online and includes a very quick and fair peer-review system, which is all easy to use. Visit http://www.dovepress.com/testimonials.php to read real quotes from published authors. 